\title{
Priming exercise accelerates pulmonary oxygen uptake kinetics during "work-to- work" cycle exercise in middle-aged individuals with type 2 diabetes
}

Norita Gildea Joel Rocha Donal O'Shea Simon Green Mikel Egaña

This is a post-peer-review, pre-copyedit version of an article published in European Journal of Applied Physiology. The final authenticated version is available online at DOI:

http://dx.doi.org/10.1007/s00421-020-04518-y 


\section{TITLE}

2 Priming exercise accelerates pulmonary oxygen uptake kinetics during "work-to-work" cycle exercise in middle-

3 aged individuals with type 2 diabetes.

\section{AUTHORS}

5 Norita Gildea ${ }^{1}$, Joel Rocha ${ }^{2}$, Donal O'Shea ${ }^{34}$, Simon Green ${ }^{5}$, Mikel Egaña ${ }^{2}$

\section{AFFILIATIONS \& ADDRESSES}

7 1. Department of Physiology, School of Medicine, Trinity College Dublin, Dublin Ireland.

8 2. Division of Sport and Exercise Sciences, Abertay University, Dundee, UK.

9 3. Department of Endocrinology, St. Columcille's Hospital, Dublin, Ireland.

10 4. Department of Endocrinology and Diabetes Mellitus, St. Vincent's University Hospital, Dublin, Ireland.

115 5chools of Health Sciences and Medicine, Western Sydney University, Sydney, Australia.

12

\section{CONTACT INFORMATION (corresponding author):}

14 Mikel Egaña

15 Department of Physiology, School of Medicine

16 Trinity College Dublin

17 Dublin 2, Ireland.

18 E-mail: $\underline{\text { megana@tcd.ie }}$

19 Telephone: +35318961770

20 Fax: +35316793545

21 ORCID: https://orcid.org/0000-0003-1984-9250 


\section{Abstract}

24 Purpose The time constant of phase II pulmonary oxygen uptake kinetics $\left(\mathrm{V}_{2} \tau_{\mathrm{p}}\right)$ is increased when high-intensity 25 exercise is initiated from an elevated baseline (work-to-work). A high-intensity priming exercise (PE), which enhances muscle oxygen supply, does not reduce this prolonged $\dot{\mathrm{V}}_{2} \tau_{\mathrm{p}}$ in healthy active individuals, likely because $\dot{\mathrm{V}} \mathrm{O}_{2} \tau_{\mathrm{p}}$ is limited by metabolic inertia (rather than oxygen delivery) in these individuals. Since $\dot{\mathrm{V}}_{2} \tau_{\mathrm{p}}$ is more influenced by oxygen delivery in type 2 diabetes (T2D), this study tested the hypothesis that PE would reduce $\mathrm{V}_{2} \tau_{\mathrm{p}}$ in T2D during work-to-work cycle exercise. Methods Nine middle-aged individuals with T2D and nine controls (ND) performed four bouts of constant-load, high-intensity work-to-work transitions, each commencing from a baseline of moderate-intensity. Two bouts were completed without PE and two were preceded by $\mathrm{PE}$. The rate of muscle deoxygenation $([\mathrm{HHb}+\mathrm{Mb}])$ and surface integrated electromyography (iEMG) were measured at the right and left vastus lateralis respectively. Results Subsequent to $\mathrm{PE}, \dot{\mathrm{V}} \mathrm{O}_{2} \tau_{\mathrm{p}}$ was reduced ( $P=0.001$ ) in T2D (from $59 \pm 17$ to $37 \pm 20$ s) but not $(P=0.24)$ in $\mathrm{ND}(44 \pm 10$ to $38 \pm 7 \mathrm{~s})$. The amplitude of the $\mathrm{V}_{2}$ slow component $\left(\dot{\mathrm{V}}_{2} \mathrm{~A}_{\mathrm{s}}\right)$ was reduced $(P=0.001)$ in both groups (T2D: $0.16 \pm 0.09$ to $0.11 \pm 0.041 / \mathrm{min}$; ND: $0.21 \pm 0.13$ to $0.13 \pm 0.091 / \mathrm{min})$. This was accompanied by a reduction in $\Delta \mathrm{iEMG}$ from the onset of $\dot{\mathrm{VO}}_{2}$ slow component to end-exercise in both groups $(P<0.001)$, while $[\mathrm{HHb}+\mathrm{Mb}]$ kinetics remained unchanged. Conclusions $\mathrm{PE}$ accelerates $\mathrm{V}_{2} \tau_{\mathrm{p}}$ in $\mathrm{T} 2 \mathrm{D}$, likely by negating the $\mathrm{O}_{2}$ delivery limitation extant in the unprimed condition, and reduces the $\dot{\mathrm{V}} \mathrm{O}_{2} \mathrm{~A}_{\mathrm{s}}$ possibly due to changes in muscle fibre activation.

Keywords: near-infrared spectroscopy, oxygen extraction, cycling, oxygen uptake slow component, electromyography.

\section{Abbreviations:}

A: Amplitude

HR: Heart rate $\mathrm{HHb}+\mathrm{Mb}$ : deoxygenated haemoglobin and myoglobin iEMG: Surface integrated electromyography MRT: Mean response time ND: Non-diabetic controls 
53 NIRS: Near-infrared spectroscopy

54 PE: Priming exercise

55 TD: Time delay

56 T2D: Type 2 diabetes

57 TOI: Tissue oxygenation index

$58 \quad \dot{\mathrm{V}} \mathrm{CO}_{2}$ : Expired carbon dioxide

$59 \dot{\mathrm{V}}_{\mathrm{E}}$ : Minute ventilation

$60 \dot{\mathrm{V}}_{2}$ : Oxygen uptake

$61 \quad \dot{V}_{2 \text { peak: }}$ Peak oxygen uptake

62 VT: Ventilatory threshold

63 w-to-w: Work-to-work transition

$64 \tau$ : time constant

$65 \Delta 50 \%$ : the sum of the power output at VT and $50 \%$ of the difference between the power output at VT and

$66 \dot{\mathrm{V}} \mathrm{O}_{2 \text { peak }}$

$67 \Delta \mathrm{iEMG}_{\text {end-TDs: }}$ : Difference between $\mathrm{iEMG}$ values at end-exercise and at the time point equivalent to the onset of $68 \mathrm{TD}$

69 
Type 2 diabetes mellitus (T2D), having reached epidemic proportions in the last two decades, poses one of the main threats to human health in the $21^{\text {st }}$ century. Of significant concern for this clinical population is the consistent demonstration of a reduced maximal exercise capacity (Green et al. 2015), which is independently correlated with cardiovascular and all-cause mortality (Kodama et al. 2009). Furthermore, pulmonary oxygen uptake $\left(\dot{\mathrm{VO}}_{2}\right)$ kinetics during moderate-intensity (i.e. below ventilatory threshold, (VT)) exercise is significantly blunted by $\sim 30 \%$ in young and middle-aged individuals with uncomplicated T2D (Mac Ananey et al. 2011; O'Connor et al. 2015; O'Connor et al. 2012; Kiely et al. 2015; Bauer et al. 2007; Regensteiner et al. 1998). This is evidenced by a prolonged time constant of the primary phase of the $\dot{\mathrm{VO}}_{2}$ kinetics response $\left(\dot{\mathrm{V}}_{2} \tau_{\mathrm{p}}\right)$ which has been considered to be a determinant of exercise tolerance (Jones and Poole 2005). Although not universal (Poitras et al. 2015; Copp et al. 2010), substantial evidence exists to suggest that the impairments in $\dot{\mathrm{V}}_{2} \tau_{\mathrm{p}}$ in uncomplicated T2D are influenced by limitations in peripheral oxygen $\left(\mathrm{O}_{2}\right)$ delivery in the lower limbs (Kiely et al. 2014; Bauer et al. 2007; MacAnaney et al. 2011). In contrast, in non-diabetic active individuals presenting with a fast $\dot{\mathbf{V}} \mathrm{O}_{2}$ kinetics, $\dot{\mathrm{V}} \mathrm{O}_{2} \tau_{\mathrm{p}}$ appears to be limited by the adjustment of specific metabolic pathways (i.e. oxidative capacity of contracting skeletal muscle) rather than $\mathrm{O}_{2}$ delivery.

In healthy active individuals, the initiation of a transition to heavy-intensity $[>\mathrm{VT}$ and $<$ critical power $(\mathrm{CP})]$ or severe-intensity $(>\mathrm{CP})$ upright cycling from a moderate-intensity $(<\mathrm{VT})$ baseline, referred to as work-to-work (w-to-w), elicits a significantly longer $\dot{\mathrm{V}}_{2} \tau_{\mathrm{p}}$ than an on-transition from rest or 'unloaded' cycling (Hughson and Morrissey 1982; Goulding et al. 2018; Wilkerson and Jones 2007, 2006; Dimenna et al. 2009; DiMenna et al. 2008). This prolonged $\dot{\mathrm{V}}_{2} \tau_{\mathrm{p}}$ may relate to a constrained cellular respiration in the already active muscle fibres (Nederveen et al. 2017), or a larger recruitment of fast twitch (type II) muscle fibres to meet the augmented metabolic demand (Whipp 1994; Barstow et al. 1996). In these healthy active individuals a prior bout of highintensity priming exercise (PE) does not alter this prolonged $\dot{\mathrm{VO}}_{2} \tau_{\mathrm{p}}$ in subsequent w-to-w transitions. This is likely because during high-intensity exercise a prior PE appears to facilitate convective and diffusive components of muscle $\mathrm{O}_{2}$ delivery (Gerbino et al. 1996; Sahlin et al. 2005; Jones et al. 2006) rather than muscle metabolic pathways. In this regard, DiMenna et al. (DiMenna et al. 2010b) reported that PE significantly reduced $\mathrm{V}_{2} \tau_{\mathrm{p}}$ during severe-intensity w-to-w cycling in the supine posture, where $\mathrm{O}_{2}$ delivery is limited due to a loss of gravityenhanced perfusion pressure in active muscle. These effects were, therefore, likely owing to an enhanced 
$100 \quad \dot{\mathrm{V}} \mathrm{O}_{2} \tau_{\mathrm{p}}$ during heavy/severe-intensity w-to-w upright cycling in healthy active participants, PE reduces the mean

101 response time (MRT) of the overall $\dot{\mathrm{V}}_{2}$ dynamic response by increasing the amplitude of the $\dot{\mathrm{V}}_{2}$ primary phase

$102\left(\dot{\mathrm{VO}}_{2} \mathrm{~A}_{\mathrm{p}}\right)$ and/or blunting the amplitude of the $\dot{\mathrm{V}} \mathrm{O}_{2}$ slow component $\left(\dot{\mathrm{V}}_{2} \mathrm{~A}_{\mathrm{s}}\right)$, which have been associated with

103 a PE-induced reduction in the requirement for type II muscle fibre activation, and thus, an improved metabolic

104 stability of type I fibres (DiMenna et al. 2008).

105

106 Given that T2D is a disease that affects the vasculature and limits the $\mathrm{O}_{2}$ supply to contracting muscle, the 107 combination of a PE intervention with the w-to-w model may offer further insight into potential mechanisms 108 implicated in the impaired $\mathrm{V}_{2}$ kinetics response demonstrated by these individuals. Accordingly, the aim of the 109 present study was to investigate the influence of $\mathrm{PE}$ on $\mathrm{V}_{2}$ kinetics during w-to-w upright cycling exercise 110 transitions in middle-aged individuals with T2D. We hypothesized that PE would speed $\mathrm{VO}_{2} \tau_{\mathrm{p}}$ in the subsequent 111 high-intensity w-to-w transition in individuals with T2D. Given that muscle fibre distribution appears to be altered 112 in individuals with T2D (Marin et al. 1994) with reports showing a 2-fold increase in type IIb fibres (Mogensen 113 et al. 2007), together with the notion that PE induces a reduction in type II muscle fibre activation, we also 114 hypothesised that PE would reduce the $\mathrm{V}_{2} \mathrm{~A}_{\mathrm{s}}$ in individuals with T2D. In attempting to explore the mechanistic 115 basis of any PE-induced effect on $\dot{\mathrm{V}}_{2}$ kinetics in $\mathrm{T} 2 \mathrm{D}$, the rate of muscle deoxygenation (i.e., deoxygenated 116 haemoglobin and myoglobin, $\mathrm{HHb}+\mathrm{Mb}$ ) and muscle electromyography (EMG) were measured to assess the 117 alterations on muscle fractional $\mathrm{O}_{2}$ extraction and motor unit activation, respectively.

\section{Methods}

120 Participants

121 Eighteen individuals, 9 with uncomplicated T2D (5 males/4 females) and 9 healthy controls (5 males/4 females) 122 volunteered to participate in this study (Table 1). Non-diabetic controls (ND) were recruited from the general 123 population, whilst participants with T2D were recruited from the Diabetes Outpatient Clinics of St. Columcille's 124 Hospital (Louglinstown, Co. Dublin) and St. Vincent's University Hospital (SVUH, Dublin 4) following chart review. To avoid the potential confounding effects of age on the T2D-related impairments in exercise tolerance,

126 previously established in men (Wilkerson et al. 2011; O'Connor et al. 2015), we limited the age of participants to $<60 \mathrm{yr}$.

128 Three female participants were premenopausal (1 T2D and $2 \mathrm{ND}$ ) and five were postmenopausal (3 T2D and 2 ND) not undergoing hormone replacement therapy. Participants were classified as physically inactive by self- 
report ( $\leq 1.5$ h.week ${ }^{-1}$ of moderate-intensity exercise in the preceding 6 months), which was confirmed by the use

131 of 5-day RT3 triaxial accelerometry (Stayhealthy Inc, CA) in a subset of participants (Table 1) (Rowlands et al.

132 2004). All participants with T2D had a clinical history of diabetes between 3 and 11 years (mean $\pm \mathrm{SD}=7.3 \pm$

$1334.0 \mathrm{yrs}$.), were treated by oral hypoglycaemic agents and had adequately controlled $\mathrm{HbA}_{1 \mathrm{c}}$ levels $(<8.5 \%)$. None

134 of the participants with T2D were taking insulin or beta-blockers and all participants were non-smokers (had not smoked during the 12-month period preceding the study). One of the healthy controls was on a prescriptive medication (statins, $n=1)$, and individuals with T2D were taking oral $(n=8)$ and/or subcutaneous $(n=1)$ hypoglycaemic prescription medications (metformin, $n=5$; sulphonylurea, $n=1$; glucagon-like peptide $1, n=1$; sodium glucose cotransporter-2 inhibitors, $n=1$; dipeptidyl peptidase-4 inhibitors, $n=1$ ). In addition, 3 individuals with T2D were taking antihypertensive prescription drugs (angiotensin converting enzyme inhibitor

$140 \&$ calcium channel blocker, $n=2$; angiotensin II receptor blocker, $n=1$ ) and statins. All participants displayed no clinical evidence of coronary artery disease (12-lead electrocardiogram treadmill stress test following the Bruce

142 protocol), peripheral arterial disease $(0.9<$ Ankle-Brachial Index, ABI, $<1.3)$, kidney dysfunction (consistent urinary protein $>200 \mathrm{mg}^{-1 l^{-1}}$ ) or liver dysfunction (urinary creatinine levels $>2.2 \mathrm{mg} \cdot \mathrm{dl}^{-1}$ ). All participants

144 provided written informed consent prior to participation. The study was approved by the Faculty of Health Sciences' Research Ethics Committee, Trinity College Dublin, and St Vincent's Healthcare Ethics and Medical Research Committee, and was performed in line with the principles outlined by the Declaration of Helsinki.

Study Protocol

Overview. Following the satisfactory completion of the 12-lead ECG stress test, all participants completed two visits to the laboratory. The controls undertook these tests in the cardiovascular performance laboratory in the Department of Physiology, Trinity College Dublin; whilst individuals with T2D did so in the exercise testing

152 facility in St. Columcille's Hospital. In the first visit all participants performed a ramp incremental (RI) cycling test to exhaustion to determine $\dot{\mathrm{V}}_{2 \text { peak }}$ (see visit 1). In the second visit participants performed four w-to-w step

154 transitions to high-intensity exercise commencing from a baseline of moderate-intensity exercise. Two of these transitions were completed without PE and the other two transitions were undertaken preceded by a PE (see visit

156 2). All exercise tests were carried out in an upright position on an electrically braked cycle ergometer (Excalibur Sport; Lode B.V., Groningen, Netherlands). All participants were asked to refrain from consuming alcohol, caffeine and non-prescribed nutritional supplements as well as avoiding any strenuous exercise in the 24 hours prior to testing. All premenopausal participants were tested during the mid-follicular phase (days 5-12) of the 
160 menstrual cycle to avoid potential differences, even though the phase of the menstrual cycle does not seem to

161 affect the $\dot{\mathrm{VO}}_{2}$ kinetics response (Mattu et al. 2020). The mid-follicular phase was self-determined.

162

163 Visit 1: Ramp incremental cycling test to exhaustion. The test started with an initial workload of $10 \mathrm{~W}$ for $2 \mathrm{~min}$

164 (i.e. 'unloaded' cycling). This was followed by 10-15 W/min increments in power output for women or 15-20

$165 \mathrm{~W} / \mathrm{min}$ increments for men based on participants' activity levels. Pedalling rate was held constant at an

166 individually selected cadence between 60-75 revolutions per minute (rpm) and was maintained throughout all

167 further testing. Failure in a test was determined as a drop in cadence exceeding $10 \mathrm{rpm}$ for $>5 \mathrm{~s}$. Peak workload

168 was the power output achieved at the point of failure. $\dot{\mathrm{V}} \mathrm{O}_{2 \text { peak }}$ was the highest $\dot{\mathrm{V}} \mathrm{O}_{2}$ value (15-s average) attained

169 during the test. The first ventilatory threshold (VT) was determined by visual inspection as the $\mathrm{VO}_{2}$ at which

$170 \quad \dot{\mathrm{V}}_{\mathrm{E}} / \dot{\mathrm{V}}_{2}$ exhibited a systematic non-linear increase without a concomitant increase in $\dot{\mathrm{V}}_{\mathrm{E}} / \dot{\mathrm{VCO}}_{2}$ and the deflection

171 point of $\dot{\mathrm{V} C O}$ vs. $\dot{\mathrm{V} O} 2$ (V-slope method) during the ramp incremental test (Beaver et al. 1986). The respiratory

172 compensation point (RCP) was estimated by identifying the second non-linear increase of $\dot{\mathrm{V}}_{\mathrm{E}}$ and $\dot{\mathrm{VCO}}_{2}$, whereby

173 an increase in $\dot{\mathrm{V}}_{\mathrm{E}} / \dot{\mathrm{V}} \mathrm{O}_{2}$ is accompanied by an increase of $\dot{\mathrm{V}}_{\mathrm{E}} / \dot{\mathrm{V}}^{\mathrm{CO}} \mathrm{O}_{2}$ (Wasserman and McIlroy 1964).

174

Visit 2: Priming effect on high-intensity work-to-work cycling exercise. All participants performed four separate W-to-w transitions to constant-load high-intensity cycling at $50 \%$ delta $(\Delta 50 \%$; the sum of the power output at VT and $50 \%$ of the difference between the power output at $\mathrm{VT}$ and $\dot{\mathrm{V}} \mathrm{O}_{2 \text { peak }}$ obtained during the ramp incremental test) each commencing from an elevated baseline of $80 \%$ VT ( $80 \%$ of each participant's VT). For all participants the power output at $\Delta 50 \%$ was higher or the same than at RCP (see results). Given that in the present study the mean response times of $\dot{\mathrm{VO}}_{2}$ during the ramp cycle exercise (Keir et al. 2018) were not accounted for when calculating these target power outputs, it is likely that power outputs at RCP (and at VT) were slightly overestimated. Thus,

182 it is reasonable to assume that the $\Delta 50 \%$ intensity for participants in the present study was within the lower region

183 of the severe intensity domain (> critical power). The order of these bouts was fixed for all participants (Fig 1).

184 Each transition consisted of 3 min of "unloaded" cycling at 10W, immediately followed by 6 min of moderateintensity ( $80 \%$ VT) cycling which in turn was immediately followed by 6 min of high-intensity $(\Delta 50 \%)$ cycling.

186 Two of these w-to-w transitions were completed without PE (unprimed w-to-w) and two bouts were undertaken preceded by a bout of PE (primed w-to-w). The unprimed w-to-w bout was used as PE. A pilot study carried out in our laboratory in young control individuals $(n=6)$ demonstrated that when a w-to-w bout was used as PE, its 
single 6 -min $50 \% \Delta$ bout was used as PE. Exercise was performed continuously with changes in power output

191 initiated as a step function without giving prior warning to the individual. There was a $12 \mathrm{~min}$ rest period between

192 each of the cycling bouts, except following the first primed w-to-w bout where participants remained seated in a

193 chair for $45 \mathrm{~min}$. This resting period has been shown to be sufficient for physiological parameters to return to

194 baseline levels, and therefore, not to influence $\dot{\mathrm{VO}}_{2}$ kinetics responses during subsequent exercise (Burnley et al.

195 2006). Eight participants (4 from each group) failed to complete 6 min of exercise at $\Delta 50 \%$ during the w-to-w

196 bouts in the unprimed condition, so only physiological responses collected over the same period (i.e., $<6 \mathrm{~min}$,

197 range $2.5-5 \mathrm{~min}$ ) during the unprimed and primed conditions were analysed. Heart rate (HR), gas

198 exchange/ventilatory variables, muscle oxygenation \& deoxygenation and muscle EMG were continuously

199 measured during each cycling bout.

200

201

Measurements

202 During exercise, participants wore a facemask to continuously collect expired air using an online metabolic system

203 (Innocor, Innovision A/S, Odense, Denmark) that measured airflow using a pneumotachometer. Carbon dioxide

204 analysis was performed by using a photoacoustic gas analyser and oxygen was analysed using an oxygen sensor

205 (Oxigraf Inc., USA) based on the principle of laser diode absorption spectroscopy. The system was calibrated

206 prior to each test as per manufacturer's recommendations. Both the oxygen sensor and photoacoustic gas analyser

207 require multi-point calibration that is routinely performed by the manufacturer every 6-12 months. Analysis of

208 expired air allowed determination of pulmonary $\mathrm{O}_{2}$ uptake $\left(\dot{\mathrm{V}}_{2}\right), \mathrm{CO}_{2}$ output $\left(\dot{\mathrm{V}} \mathrm{CO}_{2}\right)$, minute ventilation $\left(\dot{\mathrm{V}}_{\mathrm{E}}\right)$

209 and the respiratory exchange ratio breath-by-breath. HR was recorded every $5 \mathrm{~s}$ (Polar S610i, Polar Ltd, Finland),

210 with peak HR defined as the highest HR attained within the last $15 \mathrm{~s}$ prior to termination of the test.

211

212 A continuous wave NIRS system (Hamamatsu Niro 200Nx; Hamamatsu Photonics, Hamamatsu, Japan), was used

213 to determine muscle oxygenation status non-invasively through the spatially resolved spectroscopy technique and

214 modified Beer-Lambert principle with three wavelengths of emitting light $(\lambda=735,810$, and $850 \mathrm{~nm})$. The

215 theoretical basis of NIRS and its use in exercise measurements have been described in detail elsewhere (Ferrari et

216 al. 2011) but briefly, this technique estimates the optical density changes of oxygenated $\left(\mathrm{O}_{2} \mathrm{Hb}+\mathrm{Mb}\right)$ and

217 deoxygenated haemoglobin and myoglobin $(\mathrm{HHb}+\mathrm{Mb})$ based on the oxygen dependency of absorption changes

218 for near-infrared light in these proteins. As the vastus lateralis $(\mathrm{VL})$ muscle is a dominant locomotor muscle during

219 cycling, the present study examined the concentration of $\mathrm{HHb}+\mathrm{Mb}(\Delta[\mathrm{HHb}+\mathrm{Mb}])$, and tissue oxygenation index 
220 (TOI) of the right vastus lateralis (VL) muscle. After shaving, cleaning and drying the skin, the probes were placed 221 on the belly of the muscle, $5-8 \mathrm{~cm}$ above the lateral femoral condyle, parallel to the major axis of the thigh with a $2223 \mathrm{~cm}$ spacing between the emitter and receiver. The probes were housed in a black rubber holder and secured on the skin surface with bi-adhesive tape and then covered with a dark elastic bandage, which minimised extraneous movement and the intrusion of stray light throughout the exercise protocol. Since the depth of the measured area was estimated to be approximately one-half the distance between the emitter and the receiver $(\sim 1.5 \mathrm{~cm})$, the present study determined the thickness of the skin and adipose tissue at the site of the probe placement via 2D ultrasound operating in B-mode (Zonare Ultra Smart Cart, Software version 4.7, USA), to ensure that data largely represented absorption of near-infrared light in muscle tissue and not in subcutaneous fat. Individuals presenting with adiposity $>1.5 \mathrm{~cm}$ over the site of interrogation on the vastus lateralis were excluded from the study.

231 Neuromuscular activity of the vastus lateralis muscle of the left leg was measured using surface electromyography 232 (EMG). The area of the belly of the muscle was shaved and cleaned using a sterile alcohol wipe and the electrodes were placed in a bipolar $\mathrm{Ag} / \mathrm{AgCl}$ arrangement $25 \mathrm{~mm}$ apart (centre to centre) and in a plane which was estimated to be parallel to the direction of the muscle shortening during contraction, while a third ground electrode was placed on the left hip. The electrodes were taped in place and covered in a cloth bandage to prevent excessive movement during exercise. The EMG signal was measured using a Powerlab 26T (AD instruments, Sydney, Australia) at a sampling frequency of 1,000 Hz. All raw EMG data were demeaned and band passed filtered between 20 and $500 \mathrm{~Hz}$ with the filtered data then used to calculate integrated EMG (iEMG). Filtered data was rectified and then integrated for every $50 \mathrm{~ms}$ of EMG activity. The iEMG data were averaged in $15 \mathrm{~s}$ intervals throughout exercise, with these values normalized to the average measured during $15-165 \mathrm{~s}$ of unloaded cycling before the initial transition. Therefore, all iEMG data were calculated as a percentage of the initial unloaded cycling phase. Data from repeat trials were averaged, and iEMG at the time point equivalent to the onset of the $\dot{\mathrm{V}} \mathrm{O}_{2}$ slow component $\left(\mathrm{TD}_{\mathrm{s}}\right.$, see data analysis) (the $15 \mathrm{~s}$ interval before the $\mathrm{TD}_{\mathrm{s}}$ time point) and at end exercise

244 (last $15 \mathrm{~s}$ of exercise) were calculated. $\Delta \mathrm{iEMG}_{\text {end-TDs }}$ was calculated as the difference between iEMG values at end-exercise and at the time point equivalent to the onset of $\mathrm{TD}_{\mathrm{s}}$. The $\mathrm{EMG}$ recordings were re-started prior to each w-to-w transition (i.e. upon initiation of the 3 min "unloaded" cycling) and were continuously measured for the duration of each w-to-w transition. 
$\dot{V} \mathrm{O}_{2}$ Kinetics: The breath-by-breath $\dot{\mathrm{V}}_{2}$ data for each transition were linearly interpolated to provide second-bysecond values and time aligned such that time 0 represented the onset of exercise. Data from each transition were ensemble-averaged to yield a single, average response for each individual and further time-averaged into $5 \mathrm{~s}$ bins.

253 During the moderate-intensity bouts, 5 participants (2 T2D and 3 ND during both conditions) revealed a small

$254 \dot{\mathrm{VO}}_{2}$ slow component suggesting that the power outputs in these participants were slightly above their VT. This was likely because the mean response times of $\dot{\mathrm{V}}_{2}$ during the ramp cycle exercise were not accounted for when calculating the target power outputs (Keir et al. 2018). Thus, averaged and smoothed responses for each participant for moderate-intensity exercise were fitted to either a monoexponential (Eq. I) or biexponential (Eq. 2) function, while for high-intensity exercise responses were fitted to a biexponential function

$\dot{\mathrm{V}} \mathrm{O}_{2}(t)=\dot{\mathrm{V}} \mathrm{O}_{2}$ baseline $+\mathrm{A}_{\mathrm{p}}\left[1-\mathrm{e}^{-(t \mathrm{TDp}) / \mathrm{pp})}\right] \mathrm{F} 1+\mathrm{A}_{\mathrm{s}}\left[1-e^{-(\mathrm{t}-\mathrm{TDs}) / \mathrm{ss})}\right] \cdot \mathrm{F} 2$

where $\dot{\mathrm{V}} \mathrm{O}_{2}(t)$ represents the absolute $\dot{\mathrm{V}} \mathrm{O}_{2}$ at a given time $t ; \dot{\mathrm{V}}_{2}$ baseline (for moderate-intensity, in $E q$ 's 1 \& 2) is the mean $\dot{\mathrm{VO}}_{2}$ in the final 30 s of unloaded cycling, whereas $\dot{\mathrm{VO}}_{2}$ baseline (for high-intensity, in $E q$. 2) is the mean $\dot{\mathrm{V}}_{2}$ in the final $60 \mathrm{~s}$ of the moderate-intensity cycling exercise preceding the step transition to high-intensity cycling exercise; $\mathrm{A}_{\mathrm{p}}$ and $\mathrm{A}_{\mathrm{s}}$, are the amplitudes of the increase in $\dot{\mathrm{V}} \mathrm{O}_{2}$ for the primary and slow component phases; $\mathrm{TD}_{\mathrm{p}}$ and $\mathrm{TD}_{\mathrm{s}}$ are the time delays of these phases, and $\tau_{\mathrm{p}}$ and $\tau_{\mathrm{s}}$ are the time constants of the phases, defined as the duration of time for which $\dot{\mathrm{V}}_{2}$ increases to a value equivalent to $63 \%$ of the amplitude. The conditional expressions F1 and F2 limit the fitting of the phase to the period at and beyond the time delay associated with that phase. The first $20 \mathrm{~s}$ of data after the onset of exercise (i.e., the phase I $\mathrm{V}_{2}$ response) were deleted, while still allowing TD to vary freely (to optimize accuracy of parameter estimates (Murias et al. 2011)). The MRT was calculated through the fitting of a monoexponential curve to provide information on the "overall" $\dot{\mathrm{VO}}_{2}$ kinetics during the high-intensity exercise bout, with no distinction made for the various phases of the response. The $\mathrm{V}_{2}$

274 data were fit using a weighted least-squares non-linear regression procedure (TableCurve 2D, Systat, USA). Data points lying outside the $95 \%$ prediction interval during the initial fit of a model were excluded. For moderateintensity exercise only estimates representing the primary phase are presented. Whilst the presence of a slow component was detected in 5 participants during the moderate-intensity bouts, the presence of this phase does not appear to significantly affect the parameter estimates of the earlier phases (Wilkerson et al. 2004). The endexercise $\dot{\mathrm{V}}_{2}$ response, referred to as End A, was calculated as the averaged $\dot{\mathrm{VO}}_{2}$ over the last 30 s. Because the 
asymptomatic value $\left(\mathrm{A}_{\mathrm{s}}\right)$ of the exponential term describing the $\dot{\mathrm{V}}_{2}$ slow component may represent a higher

281 value than is actually reached at the end of the exercise, the actual amplitude of the slow component was calculated

282 as the absolute difference between the End $\mathrm{A}$ and $\dot{\mathrm{V}}_{2}$ baseline $+\mathrm{A}_{\mathrm{p}}$. The amplitude of the slow component was

283 also described relative to the entire $\dot{\mathrm{V}}_{2}$ response [i.e. $\mathrm{A}_{\mathrm{s}} /\left(\mathrm{A}_{\mathrm{p}}+\mathrm{A}_{\mathrm{s}}\right)$ ]. The functional "gain" of the primary $\dot{\mathrm{VO}}_{2}$

284 response $\left(\mathrm{G}_{\mathrm{p}}\right)$ was calculated as the difference between $\dot{\mathrm{VO}}_{2} \mathrm{~A}_{\mathrm{p}}$ and $\dot{\mathrm{V}}_{2}$ baseline normalized to the difference in

285 power outputs between the moderate-intensity exercise and unloaded cycling; and the functional gain of the entire

286 response at the end of the high-intensity exercise bout (i.e. end-exercise gain) was calculated in a similar manner.

$288[H H b+M b]$ kinetics and TOI. To provide information on muscle deoxygenation throughout the protocol, we modelled the $[\mathrm{HHb}+\mathrm{Mb}]$ response for moderate- and high-intensity exercise, fitting the data to either a monoexponential (Eq. 1) or biexponential (Eq. 2) function (see above). In the moderate-intensity exercise the 5 participants who showed a small $\dot{\mathrm{VO}}_{2}$ slow component also showed a $[\mathrm{HHb}+\mathrm{Mb}]$ slow component, so, for these participants data were fitted using a biexponential function, but only estimates representing the primary phase are presented. As per the $\dot{\mathrm{VO}}_{2}$ data, the NIRS-derived $\Delta[\mathrm{HHb}+\mathrm{Mb}]$ data for each transition were linearly interpolated to provide second-by-second values and time aligned. Data from each transition were ensemble-averaged to yield a single average response for each individual, and further time-averaged into $5 \mathrm{~s}$ bins. A time delay (TD) at the onset of exercise occurs in the $[\mathrm{HHb}+\mathrm{Mb}]$ profile before it increases with an exponential like time course

297 (DeLorey et al. 2003) which has been interpreted to reflect a tight coupling between muscle $\mathrm{O}_{2}$ uptake and local

$298 \mathrm{O}_{2}$ delivery (DeLorey et al. 2003). This was determined in the present study via visual inspection as a systematic increase above the pre-transition level. $[\mathrm{HHb}+\mathrm{Mb}]$ data were fitted from the end of this TD to the end of the exercise bout. For the moderate- and high-intensity exercise, the time course for the primary phase of the $\Delta[\mathrm{HHb}+\mathrm{Mb}]$ response, referred to as the effective response time $\left(\tau^{\prime} \Delta[\mathrm{HHb}+\mathrm{Mb}]\right)$, was determined from the sum of the TD and $\tau$ from the onset of exercise. TOI was determined at baseline (30 s prior to each transition to the moderate-intensity domain), at every minute during the moderate-intensity cycling exercise; at min 1 and 2 into

304 the high-intensity exercise transition ( $15 \mathrm{~s}$ bins centred on every $60 \mathrm{~s}$ ), and at the end exercise (final $30 \mathrm{~s}$ ) to allow comparisons between conditions in all participants.

Statistical analysis

308 Prior to analysis, normal distribution was assessed using the Shapiro-Wilk's test. Physical characteristics and physiological responses derived from the ramp test between groups were compared using the unpaired Student's 
310 t-test for parametric analyses, or the Mann-Whitney U test for non-parametric analyses. The kinetics parameter

311 estimates for $\dot{\mathrm{VO}}_{2}$ and $[\mathrm{HHb}+\mathrm{Mb}]$, and $\Delta \mathrm{iEMG}_{\text {end-TDs }}$ responses were analysed by using a two-way repeated 312 measures ANOVA [condition (unprimed, primed) x diabetes status (T2D, ND)] and the post hoc Tukey test. TOI

313 responses at different time points within the w-to-w transitions were compared using a 3-way repeated measures

314 ANOVA (time $\mathrm{x}$ condition $\mathrm{x}$ diabetes status). Finally, correlations between PE-induced absolute changes in $\dot{\mathrm{VO}}_{2}$

$315 \mathrm{~A}_{\mathrm{s}}$ and $\triangle \mathrm{iEMG}$ end-TDs were established using the Pearson product-moment correlation coefficient (Pearson r). A

316 power analysis indicated that 9 participants per group were required to detect a PE-induced reduction of $\sim 30 \%$ in

$317 \dot{\mathrm{VO}_{2}} \tau_{\mathrm{p}}$ during the w-to-w transitions (primary outcome) with a power of 0.80 and alpha of 0.05 . This was based

318 on previously published data on the effect of PE on subsequent $\dot{\mathrm{V}}_{2} \tau_{\mathrm{p}}$ during cycling w-to-w transitions in the

319 supine posture (i.e. when $\mathrm{O}_{2}$ delivery to the active muscles was reduced at the outset) (DiMenna et al. 2010b).

320 Statistical significance was accepted as $P<0.05$. All values are expressed as mean \pm standard deviation (SD) or as median and interquartile ranges for data that were deemed not normally distributed.

322

323

\section{Results}

324

Physical characteristics and activity levels.

Participants' physical characteristics are presented in Table 1. Both groups were well matched according to sex, age, body mass, body mass index and activity levels. As expected, participants with T2D displayed higher $\mathrm{HbA}_{1 \mathrm{c}}$ and fasting plasma glucose levels.

Performance data from ramp incremental cycling test

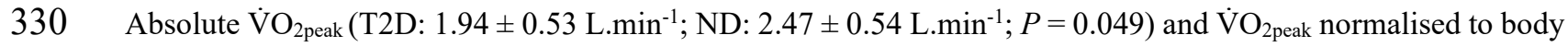
mass (T2D: $22.4 \pm 4.3 \mathrm{~mL} \cdot \mathrm{kg}^{-1} \cdot \mathrm{min}^{-1}$; ND: $29.7 \pm 7.7 \mathrm{~mL} \cdot \mathrm{kg}^{-1} \cdot \mathrm{min}^{-1} ; P=0.012$ ) were significantly reduced in individuals with T2D compared with healthy controls while peak power output tended to be lower in T2D (T2D: $149 \pm 45 \mathrm{~W}$; ND: $192 \pm 57 \mathrm{~W} ; P=0.092$ ). The power outputs equivalent to $80 \% \mathrm{VT}$ were lower in T2D (T2D: $64 \pm 17 \mathrm{~W}$; ND: $96 \pm 44 \mathrm{~W} ; P=0.043$ ) while power outputs equivalent to $\Delta 50 \%$ (T2D: $116 \pm 33 \mathrm{~W}$; ND: $158 \pm$ $58 \mathrm{~W} ; P=0.076)$ and RCP (T2D: $112 \pm 33 \mathrm{~W}$; ND: $153 \pm 55 \mathrm{~W} ; P=0.073$ ) showed a tendency to be reduced in diabetes. 
$\dot{V} \mathrm{O}_{2}$ kinetics. The parameter estimates of the $\dot{\mathrm{VO}}_{2}$ kinetics response for the high-intensity exercise bouts with and

341 without a prior PE are presented in Table 2, and responses for representative individuals are shown in Fig 2. In

342 the unprimed transition the $\dot{\mathrm{V}}_{2} \tau_{\mathrm{p}}$ and overall $\dot{\mathrm{V}}_{2}$ MRT were significantly ( $P=0.035 \& P=0.049$ respectively)

343 longer in T2D compared with controls. PE resulted in a significant reduction in the $\mathrm{V}_{2}$ MRT in both groups,

344 while $\mathrm{V}_{2} \tau_{\mathrm{p}}$ values were also reduced following PE in T2D $(P=0.001)$ but not in controls $(P=0.24)$. Subsequent

345 to $\mathrm{PE} \dot{\mathrm{V}}_{2} \mathrm{~A}_{\mathrm{s}}$ was reduced in both groups $(P=0.001)$ while $\dot{\mathrm{V}}_{2} \mathrm{~A}_{\mathrm{p}}$ was elevated (main effect, priming condition,

$346 P=0.015)$.

$347 \Delta[H H b+M b]$ kinetics. Kinetics parameters for $\Delta[\mathrm{HHb}+\mathrm{Mb}]$ as well as TOI baseline \& amplitude values are 348 displayed in Table 3 while TOI values during the w-to-w transitions are shown in Fig 3. In the unprimed condition,

349 the parameter estimates for the $[\mathrm{HHb}+\mathrm{Mb}]$ kinetics responses were similar between groups. PE induced a

350 reduction in the $\Delta[\mathrm{HHb}+\mathrm{Mb}] \mathrm{A}_{\mathrm{p}}$ in both groups (main effect, priming condition, $P=0.004$ ), but it did not affect

351 the effective response time of the $\Delta[\mathrm{HHb}+\mathrm{Mb}]$ response in either group. TOI values were higher during the primed

352 high-intensity exercise bout in both groups (main effect, priming condition, $P=0.002$ ). The magnitude of the

353 change in TOI from baseline to end-exercise was not affected by prior PE. Participants with T2D showed lower

354 TOI than controls (main effect, diabetes status, $P=<0.001$ ).

$355 E M G$. Representative iEMG responses during the w-to-w transitions are shown in Fig 4, while relative iEMG

356 responses between the time points equivalent to end-exercise and the onset of $\dot{\mathrm{V}}_{2}$ slow component are shown in

357 Fig 5. The $\Delta \mathrm{iEMG}_{\text {end-TDs }}$ was significantly reduced subsequent to $\mathrm{PE}$ in both groups (main effect, priming

358 condition, $P=<0.001$ ) (T2D unprimed: $22 \pm 18 \%$, T2D primed: $1 \pm 10 \%$; controls unprimed: $30 \pm 37 \%$, controls

359 primed: $3 \pm 20 \%$ ). Absolute changes in $\mathrm{V}_{2} \mathrm{~A}_{\mathrm{s}}$ and $\Delta \mathrm{iEMG}_{\text {end-TDs }}$ from unprimed to primed conditions were not

360 correlated in controls $(\mathrm{r}=0.09, P=0.85)$, or among individuals with $\mathrm{T} 2 \mathrm{D}(\mathrm{r}=0.49, P=0.22)$.

361

362 Effect of PE on $\dot{V} \mathrm{O}_{2}$ kinetics and NIRS-derived responses at moderate-intensity exercise of the w-to-w transition

363 The parameter estimates of the $\dot{\mathrm{V}}_{2}$ kinetics response for the moderate-intensity exercise bouts are presented in

364 Table 2. In both, the unprimed and primed conditions $\dot{\mathrm{V}}_{2} \tau_{\mathrm{p}}$ was significantly slower in $\mathrm{T} 2 \mathrm{D}$ compared with controls (main effect, group, $P=0.016$ ), while $\mathrm{PE}$ accelerated $\dot{\mathrm{V}}_{2} \tau_{\mathrm{p}}$ in both groups (main effect, priming condition, $P=0.007)$. Kinetics parameters for $\Delta[\mathrm{HHb}+\mathrm{Mb}]$ are displayed in Table 3. Parameter estimates were similar between groups in the umprimed condition. PE did not affect the amplitude or the effective response time of the $\Delta[\mathrm{HHb}+\mathrm{Mb}]$ response in either group. TOI responses were higher during the primed moderate-intensity 
exercise bout in both groups (Fig $3 \&$ Table 3 ). In addition, the magnitude of the change in TOI from baseline to

\section{Discussion}

373 To our knowledge this is the first study to explore the influence of PE on the temporal relationship between the adaptation of muscle $\mathrm{O}_{2}$ consumption and delivery during high-intensity cycling initiated from a moderateintensity baseline in T2D. In agreement with our primary hypothesis, $\mathrm{PE}$ reduced $\mathrm{V}_{2} \tau_{\mathrm{p}}$ during the high-intensity cycling bout of the w-to-w transition in $\mathrm{T} 2 \mathrm{D}$ in the absence of significant changes in the dynamic response of $\Delta[\mathrm{HHb}+\mathrm{Mb}]$. Additionally, consistent with our second hypothesis, PE significantly reduced the $\mathrm{V}_{2} \mathrm{~A}_{\mathrm{s}}$ during the high-intensity exercise bout, accompanied with a reduction in muscle electromyographic activity between the end-exercise and the time point equivalent to the onset of $\dot{\mathrm{V}}_{2}$ slow component. Together, these priming effects resulted in a reduction in the MRT of the overall $\mathrm{V}_{2}$ response.

Effect of $\mathrm{PE}$ on $\dot{\mathrm{V}} \mathrm{O}_{2} \tau_{p}$ during high-intensity exercise of the $w$-to-w transition

In the present study, PE did not significantly reduce $\mathrm{V}_{2} \tau_{\mathrm{p}}$ during the subsequent high-intensity bout of the wto-w transition among ND participants; and these findings are consistent to those observed during unprimed and primed upright severe-intensity w-to-w transitions ( $\sim 42$ vs. $\sim 42 \mathrm{~s}$ respectively) in healthy individuals (DiMenna et al. 2008). Given that $\mathrm{PE}$ facilitates convective and diffusive muscle $\mathrm{O}_{2}$ delivery, (Gerbino et al. 1996; Sahlin et al. 2005; Jones et al. 2006), our findings, and those by DiMenna et al (DiMenna et al. 2010b), suggest that the $\dot{\mathrm{V}} \mathrm{O}_{2} \tau_{\mathrm{p}}$ responses in the control condition were not impaired by $\mathrm{O}_{2}$ delivery limitation. In contrast, for T2D, $\mathrm{VO}_{2}$ $\tau_{\mathrm{p}}$ responses during w-to-w transitions following PE were significantly reduced ( $\sim 36 \%$ reduction) bringing the $\dot{\mathrm{V}} \mathrm{O}_{2} \tau_{\mathrm{p}}$ in T2D on a par with control counterparts- $(\sim 37 \mathrm{~s})$. This effect was also evidenced in healthy participants during severe-intensity cycling w-to-w transitions in the supine position (DiMenna et al. 2010b), thus, compromising exercising muscle perfusion pressure and $\mathrm{O}_{2}$ delivery (Egaña and Green 2005, 2007). Specifically,

393 PE subsequently induced a significant reduction in the lengthened $\mathrm{V}_{2} \tau_{\mathrm{p}}$ during the supine posture, aligning it with that observed in the unprimed upright posture. This was likely by negating the constrained $\mathrm{O}_{2}$ delivery, attributed to a loss of gravity-enhanced perfusion pressure in the active muscles (Jones et al. 2006; Egaña et al. 2013; Egaña et al. 2010a; Egaña et al. 2010b). 
Given that the impaired $\dot{\mathrm{VO}}_{2} \tau_{\mathrm{p}}$ in $\mathrm{T} 2 \mathrm{D}$ appears to be mediated, at least in part by limitations in $\mathrm{O}_{2}$ supply to contracting muscle (Kiely et al. 2014; Bauer et al. 2007; MacAnaney et al. 2011), it is likely that the priming-

400 induced speeding in $\mathrm{V}_{2} \tau_{\mathrm{p}}$ in $\mathrm{T} 2 \mathrm{D}$ herein was elicited by an enhanced $\mathrm{O}_{2}$ supply. The increased $\mathrm{O}_{2}$ availability 401 at exercise onset in the primed exercise bout, evidenced by the elevated TOI further substantiates this notion. It is 402 likely that this was mediated by a PE-induced greater vasodilation and muscle blood flow at the onset of exercise 403 (Hughson et al. 2003; Gerbino et al. 1996) and increased lactic acidosis, via an enhanced blood-to-myocyte $\mathrm{O}_{2}$ 404 diffusion gradient through a rightward shift of the oxyhaemoglobin dissociation curve (Boning et al. 1991; 405 Wasserman et al. 1991); even if this effect is not apparent following prior arm cranking exercise (Fukuba et al. 406 2002). However, we cannot exclude the possibility that the priming-augmented $\dot{\mathrm{V}}_{2} \tau_{\mathrm{p}}$ observed herein, was also 407 partially mediated by the upregulation of rate-limiting mitochondrial oxidative enzymes (Gurd et al. 2006, 2009).

Effect of PE on $\mathrm{VO}_{2} A_{s}$ and $i E M G$ during high-intensity exercise of the w-to-w transition

410 In the present study, in addition to decreasing $\dot{\mathrm{VO}}_{2} \tau_{\mathrm{p}}$, PE significantly reduced the amplitude of the $\dot{\mathrm{VO}}_{2}$ slow 411 component during the high-intensity bout of the w-to-w transition in participants with T2D. In addition, despite 412 PE not influencing $\mathrm{V}_{2} \tau_{\mathrm{p}}$ in the controls, $\mathrm{PE}$ reduced the $\mathrm{V}_{2} \mathrm{~A}_{\mathrm{s}}$ during the high-intensity bout, thus, shortening 413 the overall MRT of the $\dot{\mathrm{VO}}_{2}$ response. These PE-induced reductions in the $\dot{\mathrm{V}} \mathrm{O}_{2} \mathrm{~A}_{\mathrm{s}}$, without altering $\dot{\mathrm{VO}}_{2} \tau_{\mathrm{p}}$ in 414 healthy controls are in accordance with the literature centred on the influence of PE on heavy/severe-intensity 415 upright cycle exercise, both, from an elevated and an unloaded baseline (Burnley et al. 2006; Jones et al. 2008; 416 Jones et al. 2006; Scheuermann et al. 2001; Wilkerson and Jones 2007; Goulding et al. 2017; Burnley et al. 2000; 417 Fukuba et al. 2002); however, the governing mechanisms remain to be elucidated.

419 One such mechanism relates to priming-induced changes in the motor unit recruitment pattern. In this regard, in 420 the present study, the difference in iEMG between end-exercise and the time point equivalent to the onset of $\mathrm{V}_{2}$ $421 \mathrm{~A}_{\mathrm{s}}\left(\Delta \mathrm{iEMG} \mathrm{G}_{\text {end-TDs }}\right)$ in the unprimed bout was significantly reduced following PE in both groups. Our findings are 422 consistent with reductions in $\triangle \mathrm{iEMG}$ between end-exercise and min 2 during primed compared with unprimed 423 upright severe-intensity w-to-w cycling transitions in young active participants (DiMenna et al. 2008). Given the 424 transition to high-intensity exercise from an elevated baseline would mandate the recruitment of predominantly type II muscle fibres, it is plausible that PE elicited a reduction in the requirement for additional type II muscle 426 fibre activation as the exercise proceeded, and as such, the associated $\dot{\mathrm{V}}_{2}$ cost of that activation was reduced 427 (DiMenna et al. 2008). Further extending this notion, DiMenna and colleagues (Dimenna et al. 2010a) 

respectively) during prone knee-extension w-to-w transitions concomitant with a blunting of the $\triangle \mathrm{iEMG}$. A reduction in the recruitment of these less efficient muscle fibres could serve to dampen the increase in the sustained metabolic acidosis, deemed a likely driving force behind the slow components of both [PCr] and $\dot{\mathrm{V}}_{2}$, (Rossiter et al. 2002; Krustrup et al. 2004). The combined iEMG and tissue oxygenation data in the present study may also suggest a priming-enhanced distribution of intramuscular blood flow. Consequently, the anaerobic contribution would decrease, precluding the recruitment of additional motor units, whilst favouring a more homogenous pool of highly oxidative type 1 muscle fibres (DiMenna et al. 2010b). By the same token, we cannot negate the upregulation of enzymatic processes within the type I fibres already recruited, improving the metabolic stability within. Subsequently, a smaller reduction in [PCr] and Gibbs free energy of ATP hydrolysis, as well as a smaller increase in [Pi] and [ADP] are ensured, thus sparing the activation of type 1 motor units herein.

440 Given that PE herein facilitated a reduction in the $\mathrm{VO}_{2} \mathrm{~A}_{\mathrm{s}}$ of the severe-intensity w-to-w transition in individuals with $\mathrm{T} 2 \mathrm{D}$, combined with a reduction in $\Delta \mathrm{iEMG}_{\text {end-TDs }}$ of that same bout, it is likely that the priming-induced reduction in $\dot{\mathrm{V}}_{2} \mathrm{~A}_{\mathrm{s}}$ herein may also be related to modified motor unit recruitment patterns. However, in addition, given that type II fibres operate at a lower microvascular $\mathrm{PO}_{2}$, the priming-enhanced $\mathrm{O}_{2}$ delivery plausibly

444 increased the blood-to-myocyte flux and thus intramyocyte $\mathrm{PO}_{2}$. This is all the more pertinent considering an 445 altered muscle fibre distribution has been evidenced in individuals with T2D (Marin et al. 1994) showing increased 446 proportions in type IIb fibres (Mogensen et al. 2007). However, it should be noted that given the variability associated with measurement and normalisation of iEMG, some previous studies do not support the association

448 between neuromuscular activation and the $\dot{\mathrm{V}}_{2}$ slow component (Scheuermann et al. 2001). In addition, we did not observe a significant correlation between PE-induced absolute reductions in $\triangle \mathrm{iEMG}_{\text {end-TDs }}$ with reductions in $450 \quad \mathrm{~A}_{\mathrm{s}}$.

453 During the unprimed moderate-intensity cycling bout and in line with previous findings (reviewed by Green et al 454 (Green et al. 2015)), individuals with T2D displayed a significantly longer $\mathrm{V}_{2} \tau_{\mathrm{p}}$ than their healthy counterparts ( $\sim 35$ vs. $\sim 44 \mathrm{~s}$, respectively). Subsequent to PE both groups demonstrated similar reductions in the $\dot{\mathrm{VO}}_{2} \tau_{\mathrm{p}}$, consistent with recent findings from our group in a larger number of middle-aged individuals with T2D (Rocha et al. 2019), and in several previous studies involving young and older untrained healthy individuals presenting with 

deoxygenation kinetics $\left(\tau^{\prime}[\mathrm{HHb}+\mathrm{Mb}]\right)$ herein, were not affected by PE in any of the groups; therefore, it is likely

460 that the speeding of the $\dot{\mathrm{V}}_{2}$ kinetics response was attributed to a better matching of microvascular $\mathrm{O}_{2}$ delivery to 461 utilisation

\section{Limitations}

464 While a subset of participants (4 in each group) did not complete the required 6 min of high-intensity cycling exercise during the w-to-w transitions, we believe this had little influence on the interpretation of our findings given that the majority ( 8 in each group) completed at least 4 min of the bout and showed a clear $\mathrm{V}_{2}$ slow component phase. Although the current protocol did not allow the random assignment of unprimed and primed conditions, this likely has a small impact on the results given that the sequence of the exercise transitions was the same for all participants. We acknowledge the NIRS-derived oxygenation and deoxygenation data was limited to one superficial muscle. Thus, the structural and functional heterogeneity extant within individual muscles, in particular relating to vascularity and fibre type, fibre recruitment, vascular control, and blood flow (Koga et al. 2011; McDonough et al. 2005), in addition to variances identified both between muscles and within deep and superficial muscle segments (Okushima et al. 2015; Saitoh et al. 2009), warrant consideration. Additionally, 3 participants with T2D were classified as hypertensive and also had hyperlipidaemia; whereas all controls were normotensive, with one presenting with hyperlipidaemia. Further studies are needed to better establish if the higher rates of hypertension and/or hyperlipidaemia observed within the T2D group in the present study may have any significant impact on the findings presented herein.

\section{Conclusions}

480 The present study primarily demonstrated that priming exercise accelerates the primary time constant of $\dot{\mathrm{V}}_{2}$ 481 during high-intensity w-to-w transitions in middle-aged individuals with T2D. This effect was likely mediated by 482 a priming-induced increase in $\mathrm{O}_{2}$ delivery within the microvasculature of the working muscle, serving to alleviate the metabolic strain to maintain $\dot{\mathrm{V}}_{2}$. In addition, $\mathrm{PE}$ decreased the amplitude of the $\dot{\mathrm{V}} \mathrm{O}_{2}$ slow component which

484 was likely influenced by an augmented motor unit recruitment pattern. Thus, from a physiological perspective the combination of a PE intervention with the w-to-w model helps expand the insight that the impaired $\mathrm{V}_{2}$ kinetics in $\mathrm{T} 2 \mathrm{D}$ are influenced by limitations in $\mathrm{O}_{2}$ delivery. From a practical perspective, employing the work-to-work protocol is of great relevance as it replicates metabolic transitions from light to higher metabolic rates akin to 
488 those in daily life. Given individuals with T2D perceive light to moderate exercise as being more difficult than

489 healthy counterparts (Huebschmann et al. 2009), a more sedentary lifestyle is likely, which is independently

490 associated with worsening of cardiovascular outcomes in this burgeoning population. Therefore, the potential that

491 lies within an acute intervention such as priming or warm-up exercise which serves to heighten the oxidative

492 capacity of muscles and increase the therapeutic effect of exercise warrants further recognition.

493

494 Author contributions

495 N.G., J.R., M.E., D.O'S. and S.G. contributed to the study conception and design. N.G. and J.R. performed data

496 collection. N.G., and M.E. analysed data. N.G. and M.E. drafted the manuscript. S.G., D.O’S and J.R.

497 contributed to critically revising of this manuscript. All authors approved the final version.

498

\section{$499 \quad$ Funding}

500 This publication has emanated from research conducted with the financial support of the Health Research Board

501 (Grant No HRA_POR/2073/274).

502

503 Compliance with ethical standards

504 Conflict of interest Authors declare that they have no conflict of interest, financial or otherwise. 
508

509

510

511

512

513

514

515

516

517

518

519

520

521

522

523

524

525

526

527

528

529

530

531

532

533

534

535

536

537

538

539

540

541

542

543

544

545

546

547

548

549

550

551

552

553

554

555

556
Barstow TJ, Jones AM, Nguyen PH, Casaburi R (1996) Influence of muscle fiber type and pedal frequency on oxygen uptake kinetics of heavy exercise. J Appl Physiol (1985) 81 (4):16421650. doi:10.1152/jappl.1996.81.4.1642

Bauer TA, Reusch JE, Levi M, Regensteiner JG (2007) Skeletal muscle deoxygenation after the onset of moderate exercise suggests slowed microvascular blood flow kinetics in type 2 diabetes. Diabetes Care 30 (11):2880-2885. doi:dc07-0843 [pii]

\section{$10.2337 / \mathrm{dc07}-0843$ [doi]}

Beaver WL, Wasserman K, Whipp BJ (1986) A new method for detecting anaerobic threshold by gas exchange. J Appl Physiol 60 (6):2020-2027

Boning D, Hollnagel C, Boecker A, Goke S (1991) Bohr shift by lactic acid and the supply of 02 to skeletal muscle. Respir Physiol 85 (2):231-243. doi:10.1016/0034-5687(91)90064-p

Burnley M, Doust JH, Jones AM (2006) Time required for the restoration of normal heavy exercise VO2 kinetics following prior heavy exercise. J Appl Physiol 101 (5):1320-1327. doi:00475.2006 [pii]

10.1152/japplphysiol.00475.2006 [doi]

Burnley M, Jones AM, Carter H, Doust JH (2000) Effects of prior heavy exercise on phase II pulmonary oxygen uptake kinetics during heavy exercise. J Appl Physiol 89 (4):1387-1396

Copp SW, Hageman KS, Behnke BJ, Poole DC, Musch TI (2010) Effects of type II diabetes on exercising skeletal muscle blood flow in the rat. J Appl Physiol (1985) 109 (5):1347-1353. doi:10.1152/japplphysiol.00668.2010

De Roia G, Pogliaghi S, Adami A, Papadopoulou C, Capelli C (2012) Effects of priming exercise on the speed of adjustment of muscle oxidative metabolism at the onset of moderate-intensity step transitions in older adults. Am J Physiol Regul Integr Comp Physiol 302 (10):R1158-1166. doi:10.1152/ajpregu.00269.2011

DeLorey DS, Kowalchuk JM, Paterson DH (2003) Relationship between pulmonary 02 uptake kinetics and muscle deoxygenation during moderate-intensity exercise. J Appl Physiol (1985) 95 (1):113-120. doi:10.1152/japplphysiol.00956.2002

DeLorey DS, Kowalchuk JM, Paterson DH (2004) Effects of prior heavy-intensity exercise on pulmonary $\mathrm{O} 2$ uptake and muscle deoxygenation kinetics in young and older adult humans. J Appl Physiol (1985) 97 (3):998-1005. doi:10.1152/japplphysiol.01280.2003

Dimenna FJ, Fulford J, Bailey SJ, Vanhatalo A, Wilkerson DP, Jones AM (2010a) Influence of priming exercise on muscle [PCr] and pulmonary $\mathrm{O} 2$ uptake dynamics during 'work-to-work' kneeextension exercise. Respir Physiol Neurobiol 172 (1-2):15-23. doi:10.1016/j.resp.2010.04.017

Dimenna FJ, Wilkerson DP, Burnley M, Bailey SJ, Jones AM (2009) Influence of extreme pedal rates on pulmonary $\mathrm{O}(2)$ uptake kinetics during transitions to high-intensity exercise from an elevated baseline. Respir Physiol Neurobiol 169 (1):16-23. doi:10.1016/j.resp.2009.08.001

DiMenna FJ, Wilkerson DP, Burnley M, Bailey SJ, Jones AM (2010b) Priming exercise speeds pulmonary $\mathrm{O} 2$ uptake kinetics during supine "work-to-work" high-intensity cycle exercise. J Appl Physiol (1985) 108 (2):283-292. doi:10.1152/japplphysiol.01047.2009

DiMenna FJ, Wilkerson DP, Burnley M, Jones AM (2008) Influence of priming exercise on pulmonary O2 uptake kinetics during transitions to high-intensity exercise from an elevated baseline. J Appl Physiol (1985) 105 (2):538-546. doi:10.1152/japplphysiol.90357.2008

Egaña M, Columb D, O'Donnell S (2013) Effect of low recumbent angle on cycling performance, fatigue, and V O(2) kinetics. Med Sci Sports Exerc 45 (4):663-673. doi:10.1249/MSS.0b013e318279a9f2

Egaña M, Green S (2005) Effect of body tilt on calf muscle performance and blood flow in humans. J Appl Physiol (1985) 98 (6):2249-2258. doi:10.1152/japplphysiol.01235.2004

Egaña M, Green S (2007) Intensity-dependent effect of body tilt angle on calf muscle fatigue in humans. Eur J Appl Physiol 99 (1):1-9. doi:10.1007/s00421-006-0308-4 
Egaña M, O'Riordan D, Warmington SA (2010a) Exercise performance and VO2 kinetics during upright and recumbent high-intensity cycling exercise. Eur J Appl Physiol 110 (1):39-47. doi:10.1007/s00421-010-1466-y

Egaña M, Ryan K, Warmington SA, Green S (2010b) Effect of body tilt angle on fatigue and EMG activities in lower limbs during cycling. Eur J Appl Physiol 108 (4):649-656. doi:10.1007/s00421-009-1254-8

Ferrari M, Muthalib M, Quaresima V (2011) The use of near-infrared spectroscopy in understanding skeletal muscle physiology: recent developments. Philos Trans A Math Phys Eng Sci 369 (1955):4577-4590. doi:10.1098/rsta.2011.0230

Fukuba Y, Hayashi N, Koga S, Yoshida T (2002) VO(2) kinetics in heavy exercise is not altered by prior exercise with a different muscle group. J Appl Physiol (1985) 92 (6):2467-2474. doi:10.1152/japplphysiol.00207.2001

Gerbino A, Ward SA, Whipp BJ (1996) Effects of prior exercise on pulmonary gas-exchange kinetics during high-intensity exercise in humans. J Appl Physiol (1985) 80 (1):99-107. doi:10.1152/jappl.1996.80.1.99

Goulding RP, Roche DM, Marwood S (2017) Prior exercise speeds pulmonary oxygen uptake kinetics and increases critical power during supine but not upright cycling. Exp Physiol 102 (9):11581176. doi:10.1113/ep086304

Goulding RP, Roche DM, Marwood S (2018) Elevated baseline work rate slows pulmonary oxygen uptake kinetics and decreases critical power during upright cycle exercise. Physiol Rep 6 (14):e13802. doi:10.14814/phy2.13802

Green S, Egana M, Baldi JC, Lamberts R, Regensteiner JG (2015) Cardiovascular control during exercise in type 2 diabetes mellitus. J Diabetes Res 2015:654204. doi:10.1155/2015/654204

Gurd BJ, Peters SJ, Heigenhauser GJ, LeBlanc PJ, Doherty TJ, Paterson DH, Kowalchuk JM (2006) Prior heavy exercise elevates pyruvate dehydrogenase activity and speeds $\mathrm{O} 2$ uptake kinetics during subsequent moderate-intensity exercise in healthy young adults. J Physiol 577 (Pt 3):985-996. doi:10.1113/jphysiol.2006.112706

Gurd BJ, Peters SJ, Heigenhauser GJ, LeBlanc PJ, Doherty TJ, Paterson DH, Kowalchuk JM (2009) Prior heavy exercise elevates pyruvate dehydrogenase activity and muscle oxygenation and speeds $\mathrm{O} 2$ uptake kinetics during moderate exercise in older adults. Am J Physiol Regul Integr Comp Physiol 297 (3):R877-884. doi:10.1152/ajpregu.90848.2008

Gurd BJ, Scheuermann BW, Paterson DH, Kowalchuk JM (2005) Prior heavy-intensity exercise speeds VO2 kinetics during moderate-intensity exercise in young adults. J Appl Physiol (1985) 98 (4):1371-1378. doi:10.1152/japplphysiol.01028.2004

Huebschmann AG, Reis EN, Emsermann C, Dickinson LM, Reusch JE, Bauer TA, Regensteiner JG (2009) Women with type 2 diabetes perceive harder effort during exercise than nondiabetic women. Appl Physiol Nutr Metab 34 (5):851-857. doi:h09-074 [pii]

10.1139/h09-074 [doi]

Hughson R, Schijvens H, Burrows S, Devitt, D, Betik A, Hopman M (2003) Blood Flow and Metabolic Control at the Onset of Heavy Exercise. International Journal of Sport and Health Science 1 (1):9-18

Hughson RL, Morrissey M (1982) Delayed kinetics of respiratory gas exchange in the transition from prior exercise. J Appl Physiol Respir Environ Exerc Physiol 52 (4):921-929. doi:10.1152/jappl.1982.52.4.921

Jones AM, Berger NJ, Wilkerson DP, Roberts CL (2006) Effects of "priming" exercise on pulmonary $\mathrm{O} 2$ uptake and muscle deoxygenation kinetics during heavy-intensity cycle exercise in the supine and upright positions. J Appl Physiol (1985) 101 (5):1432-1441. doi:10.1152/japplphysiol.00436.2006

Jones AM, Poole DC (2005) Oxygen uptake dynamics: from muscle to mouth--an introduction to the symposium. Med Sci Sports Exerc 37 (9):1542-1550. doi:00005768-200509000-00014 [pii] 
642

643

644

645

646

647

648

649

650

651

652

653

654

655

656

657

Jones AM, Wilkerson DP, DiMenna F, Fulford J, Poole DC (2008) Muscle metabolic responses to exercise above and below the "critical power" assessed using 31P-MRS. Am J Physiol Regul Integr Comp Physiol 294 (2):R585-593. doi:10.1152/ajpregu.00731.2007

Keir DA, Pogliaghi S, Murias JM (2018) The Respiratory Compensation Point and the Deoxygenation Break Point Are Valid Surrogates for Critical Power and Maximum Lactate Steady State. Med Sci Sports Exerc 50 (11):2375-2378. doi:10.1249/mss.0000000000001698

Kiely C, O'Connor E, O'Shea D, Green S, Egaña M (2014) Hemodynamic responses during graded and constant-load plantar flexion exercise in middle-aged men and women with type 2 diabetes. J Appl Physiol (1985) 117 (7):755-764. doi:10.1152/japplphysiol.00555.2014

Kiely C, Rocha J, O'Connor E, O'Shea D, Green S, Egana M (2015) Influence of menopause and Type 2 diabetes on pulmonary oxygen uptake kinetics and peak exercise performance during cycling. Am J Physiol Regul Integr Comp Physiol 309 (8):R875-883. doi:10.1152/ajpregu.00258.2015

Kodama S, Saito K, Tanaka S, Maki M, Yachi Y, Asumi M, Sugawara A, Totsuka K, Shimano H, Ohashi $Y$, Yamada N, Sone $H$ (2009) Cardiorespiratory fitness as a quantitative predictor of all-cause mortality and cardiovascular events in healthy men and women: a meta-analysis. Jama 301 (19):2024-2035. doi:10.1001/jama.2009.681

Koga S, Poole DC, Fukuoka Y, Ferreira LF, Kondo N, Ohmae E, Barstow TJ (2011) Methodological validation of the dynamic heterogeneity of muscle deoxygenation within the quadriceps during cycle exercise. Am J Physiol Regul Integr Comp Physiol 301 (2):R534-541. doi:10.1152/ajpregu.00101.2011

Krustrup P, Soderlund K, Mohr M, Bangsbo J (2004) The slow component of oxygen uptake during intense, sub-maximal exercise in man is associated with additional fibre recruitment. Pflugers Arch 447 (6):855-866. doi:10.1007/s00424-003-1203-z

Mac Ananey O, Malone J, Warmington S, O'Shea D, Green S, Egaña M (2011) Cardiac output is not related to the slowed o2 uptake kinetics in type 2 diabetes. Med Sci Sports Exerc 43 (6):935942. doi:10.1249/MSS.0b013e3182061cdb

MacAnaney O, Reilly H, O'Shea D, Egaña M, Green S (2011) Effect of type 2 diabetes on the dynamic response characteristics of leg vascular conductance during exercise. Diab Vasc Dis Res 8 (1):12-21. doi:10.1177/1479164110389625

Marin P, Andersson B, Krotkiewski M, Bjorntorp P (1994) Muscle fiber composition and capillary density in women and men with NIDDM. Diabetes Care 17 (5):382-386

Mattu AT, lannetta D, MacInnis MJ, Doyle-Baker PK, Murias JM (2020) Menstrual and oral contraceptive cycle phases do not affect submaximal and maximal exercise responses. Scand J Med Sci Sports 30 (3):472-484. doi:10.1111/sms.13590

McDonough P, Behnke BJ, Padilla DJ, Musch TI, Poole DC (2005) Control of microvascular oxygen pressures in rat muscles comprised of different fibre types. J Physiol 563 (Pt 3):903-913. doi:10.1113/jphysiol.2004.079533

Mogensen M, Sahlin K, Fernstrom M, Glintborg D, Vind BF, Beck-Nielsen H, Hojlund K (2007) Mitochondrial respiration is decreased in skeletal muscle of patients with type 2 diabetes. Diabetes 56 (6):1592-1599. doi:10.2337/db06-0981

Murias JM, Spencer MD, Kowalchuk JM, Paterson DH (2011) Influence of phase I duration on phase II VO2 kinetics parameter estimates in older and young adults. Am J Physiol Regul Integr Comp Physiol 301 (1):R218-224. doi:10.1152/ajpregu.00060.2011

Nederveen JP, Keir DA, Love LK, Rossiter HB, Kowalchuk JM (2017) Effect of heavy-intensity 'priming' exercise on oxygen uptake and muscle deoxygenation kinetics during moderate-intensity step-transitions initiated from an elevated work rate. Respir Physiol Neurobiol 235:62-70. doi:10.1016/j.resp.2016.09.013

O'Connor E, Green S, Kiely C, O'Shea D, Egana M (2015) Differential effects of age and type 2 diabetes on dynamic vs. peak response of pulmonary oxygen uptake during exercise. J Appl Physiol (1985) 118 (8):1031-1039. doi:10.1152/japplphysiol.01040.2014 
O'Connor E, Kiely C, O'Shea D, Green S, Egaña M (2012) Similar level of impairment in exercise performance and oxygen uptake kinetics in middle-aged men and women with type 2 diabetes. Am J Physiol Regul Integr Comp Physiol 303 (1):R70-76. doi:10.1152/ajpregu.00012.2012

Okushima D, Poole DC, Rossiter HB, Barstow TJ, Kondo N, Ohmae E, Koga S (2015) Muscle deoxygenation in the quadriceps during ramp incremental cycling: Deep vs. superficial heterogeneity. J Appl Physiol (1985) 119 (11):1313-1319. doi:10.1152/japplphysiol.00574.2015

Poitras VJ, Bentley RF, Hopkins-Rosseel DH, LaHaye SA, Tschakovsky ME (2015) Independent effect of type 2 diabetes beyond characteristic comorbidities and medications on immediate but not continued knee extensor exercise hyperemia. J Appl Physiol (1985) 119 (3):202-212. doi:10.1152/japplphysiol.00758.2014

Regensteiner JG, Bauer TA, Reusch JE, Brandenburg SL, Sippel JM, Vogelsong AM, Smith S, Wolfel EE, Eckel RH, Hiatt WR (1998) Abnormal oxygen uptake kinetic responses in women with type II diabetes mellitus. J Appl Physiol 85 (1):310-317

Rocha J, Gildea N, O'Shea D, Green S, Egana M (2019) Influence of priming exercise on oxygen uptake and muscle deoxygenation kinetics during moderate-intensity cycling in type 2 diabetes. J Appl Physiol (1985) 127 (4):1140-1149. doi:10.1152/japplphysiol.00344.2019

Rossiter HB, Ward SA, Kowalchuk JM, Howe FA, Griffiths JR, Whipp BJ (2002) Dynamic asymmetry of phosphocreatine concentration and $\mathrm{O}(2)$ uptake between the on- and off-transients of moderate- and high-intensity exercise in humans. J Physiol 541 (Pt 3):991-1002. doi:10.1113/jphysiol.2001.012910

Rowlands AV, Thomas PW, Eston RG, Topping R (2004) Validation of the RT3 triaxial accelerometer for the assessment of physical activity. Med Sci Sports Exerc 36 (3):518-524

Sahlin K, Sorensen JB, Gladden LB, Rossiter HB, Pedersen PK (2005) Prior heavy exercise eliminates VO2 slow component and reduces efficiency during submaximal exercise in humans. J Physiol 564 (Pt 3):765-773. doi:jphysiol.2005.083840 [pii]

10.1113/jphysiol.2005.083840 [doi]

Saitoh T, Ferreira LF, Barstow TJ, Poole DC, Ooue A, Kondo N, Koga S (2009) Effects of prior heavy exercise on heterogeneity of muscle deoxygenation kinetics during subsequent heavy exercise. Am J Physiol Regul Integr Comp Physiol 297 (3):R615-621. doi:10.1152/ajpregu.00048.2009

Scheuermann BW, Hoelting BD, Noble ML, Barstow TJ (2001) The slow component of O(2) uptake is not accompanied by changes in muscle EMG during repeated bouts of heavy exercise in humans. J Physiol 531 (Pt 1):245-256. doi:10.1111/j.1469-7793.2001.0245j.x

Wasserman K, Hansen J, Sue D (1991) Facilitation of Oxygen Consumption by Lactic Acidosis During Exercise. News Physiol Sci 6:29-34

Wasserman K, Mcllroy MB (1964) DETECTING THE THRESHOLD OF ANAEROBIC METABOLISM IN CARDIAC PATIENTS DURING EXERCISE. Am J Cardiol 14:844-852

Whipp BJ (1994) The slow component of 02 uptake kinetics during heavy exercise. Med Sci Sports Exerc $26(11): 1319-1326$

Wilkerson DP, Jones AM (2006) Influence of initial metabolic rate on pulmonary 02 uptake onkinetics during severe intensity exercise. Respir Physiol Neurobiol 152 (2):204-219. doi:10.1016/j.resp.2005.10.001

Wilkerson DP, Jones AM (2007) Effects of baseline metabolic rate on pulmonary 02 uptake onkinetics during heavy-intensity exercise in humans. Respir Physiol Neurobiol 156 (2):203-211. doi:10.1016/j.resp.2006.09.008

Wilkerson DP, Koppo K, Barstow TJ, Jones AM (2004) Effect of work rate on the functional 'gain' of Phase II pulmonary $\mathrm{O} 2$ uptake response to exercise. Respir Physiol Neurobiol 142 (2-3):211223. doi:10.1016/j.resp.2004.06.001 
Wilkerson DP, Poole DC, Jones AM, Fulford J, Mawson DM, Ball Cl, Shore AC (2011) Older type 2 diabetic males do not exhibit abnormal pulmonary oxygen uptake and muscle oxygen utilization dynamics during submaximal cycling exercise. Am J Physiol Regul Integr Comp Physiol 300 (3):R685-692. doi:10.1152/ajpregu.00479.2010

712 
Figure 1

Unprimed Work-To-Work

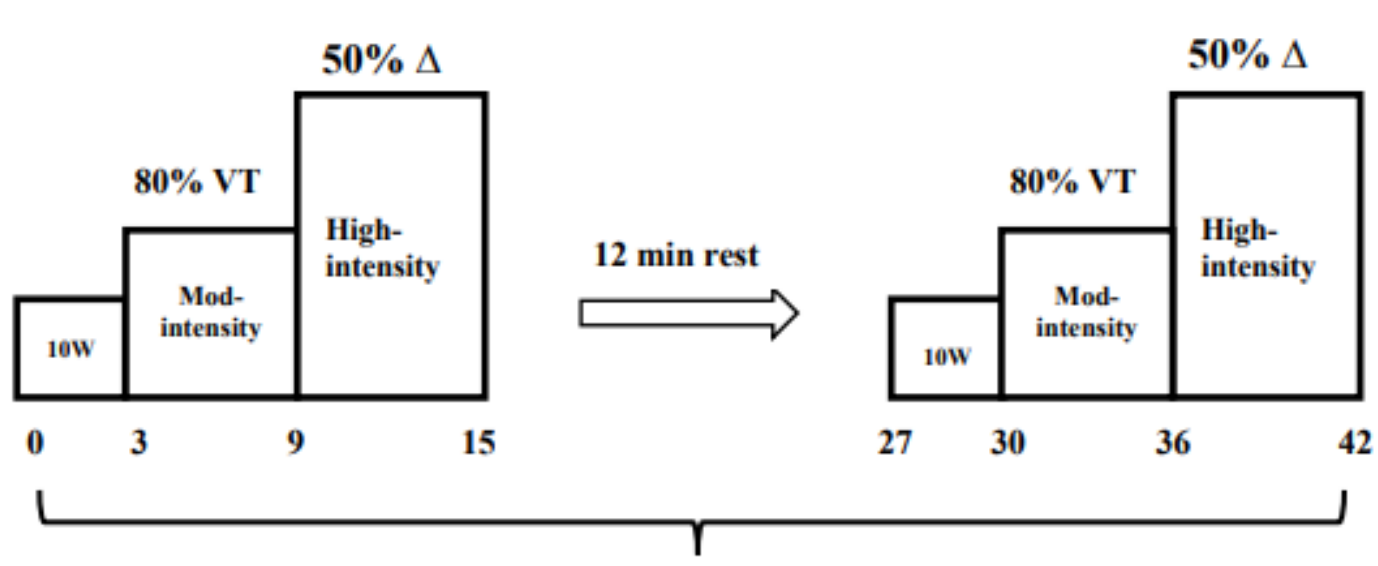

Repeated after 45 min rest
Primed Work-To-Work

717 Fig 1 Schematic representation of the protocol. Unprimed and primed work-to-work cycling step transitions

718 performed at high-intensity cycling exercise $(\Delta 50 \%$; the sum of the power output at VT and $50 \%$ of the difference

719 between the power output at $\mathrm{VT}$ and $\dot{\mathrm{V}}_{2 \text { peak }}$ ), each commencing from an elevated baseline of moderate-intensity

720 (power output corresponding to $80 \%$ of each participant's first ventilatory threshold, VT). All step transitions,

721 each lasting $6 \mathrm{~min}$, were preceded by $3 \mathrm{~min}$ of cycling at $10 \mathrm{~W}$ (i.e. 'baseline' cycling). Unprimed and primed

722 work-to-work transitions were separated by 12 min of passive rest. The 2 step transitions (unprimed and primed work-to-work) were repeated following $45 \mathrm{~min}$ of passive rest within the same laboratory visit. 
Figure 2

a)

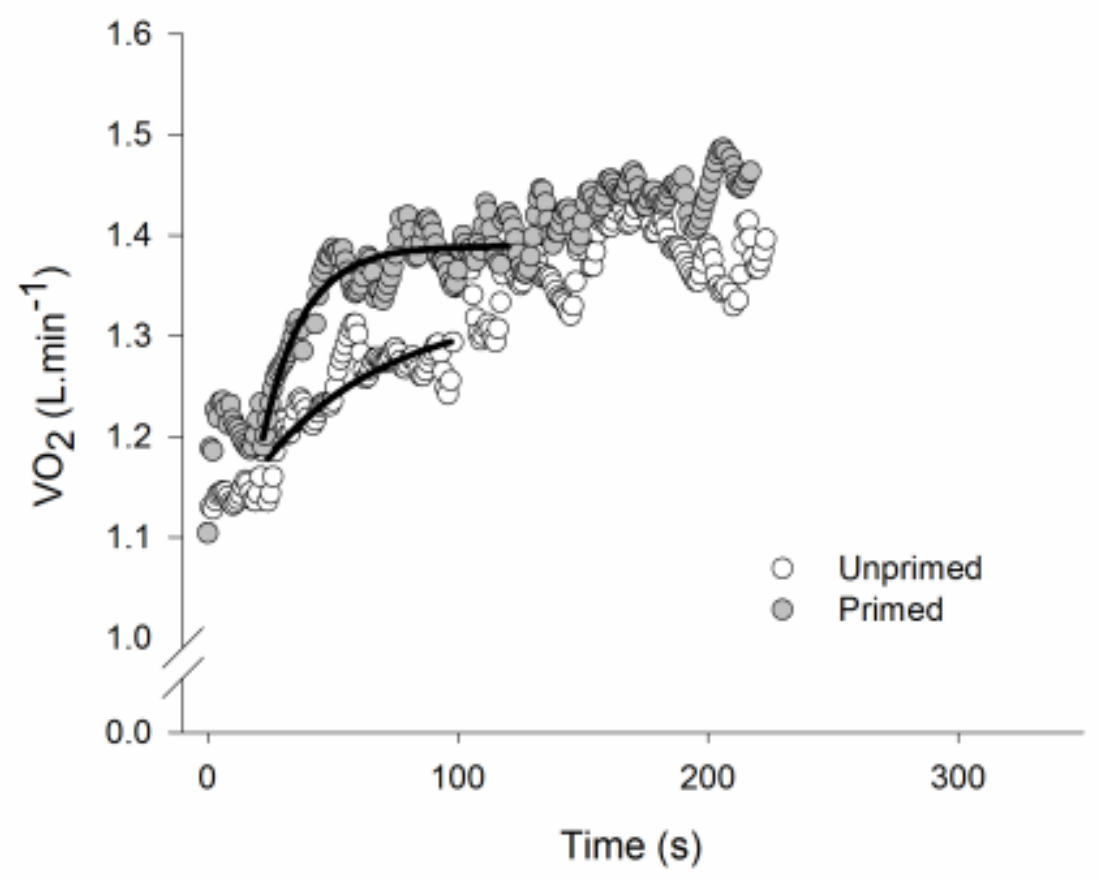

b)

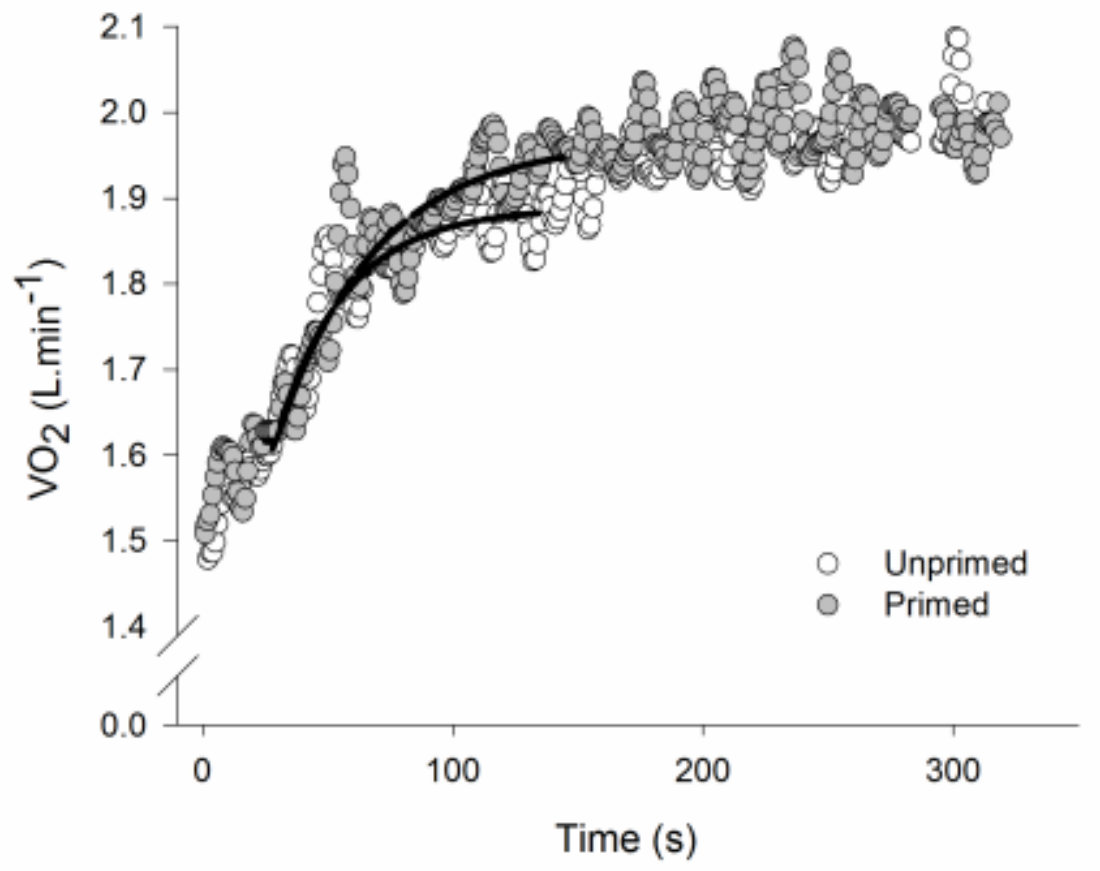

726 Fig 2. Oxygen uptake $\left(\mathrm{VO}_{2}\right)$ responses for a representative individual with type 2 diabetes (A) and a healthy 727 control (B) during high-intensity work-to-work cycling transitions without priming exercise (open circles) and 728 with priming exercise (solid circles). The continuous lines of best fit illustrate the primary phase of the oxygen uptake $\left(\dot{\mathrm{V}}_{2}\right)$ response. Note the relatively slower response of the primary phase of the $\dot{\mathrm{V}} \mathrm{O}_{2}$ response in the 
Figure 3

a)

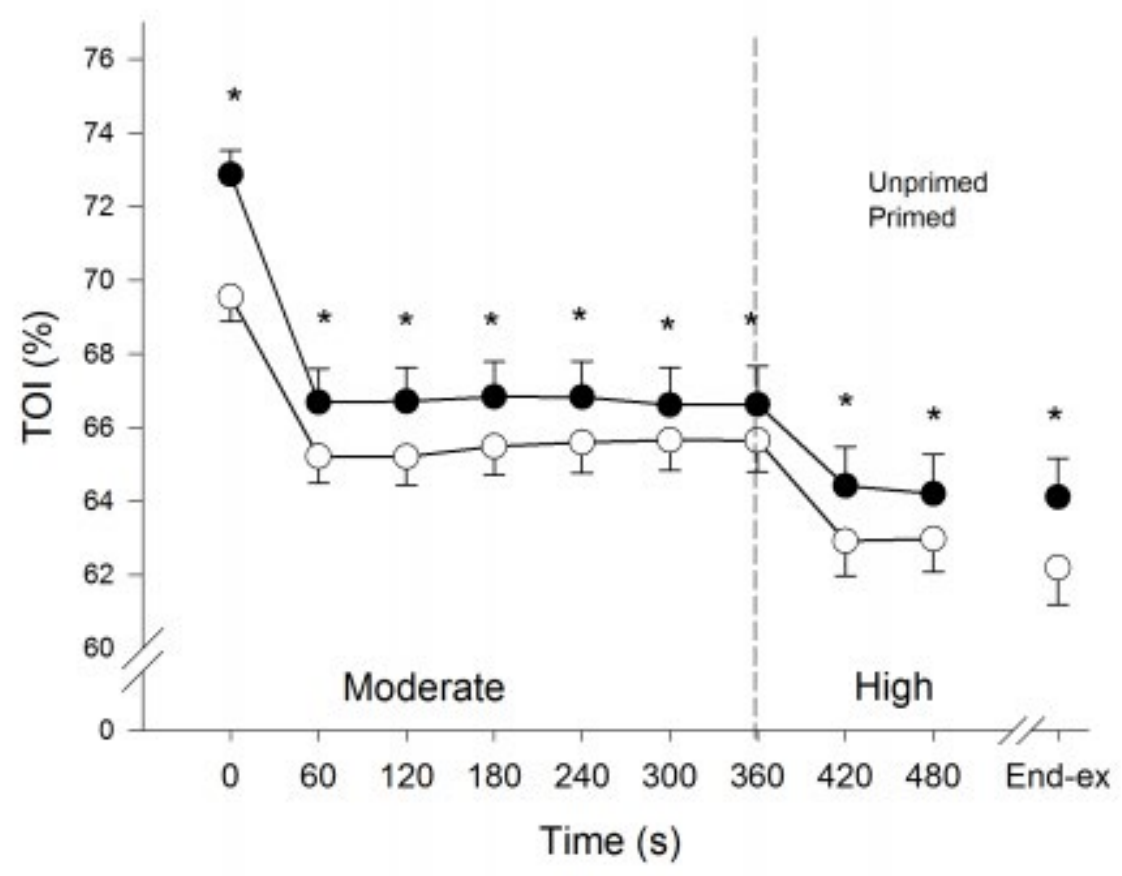

b)

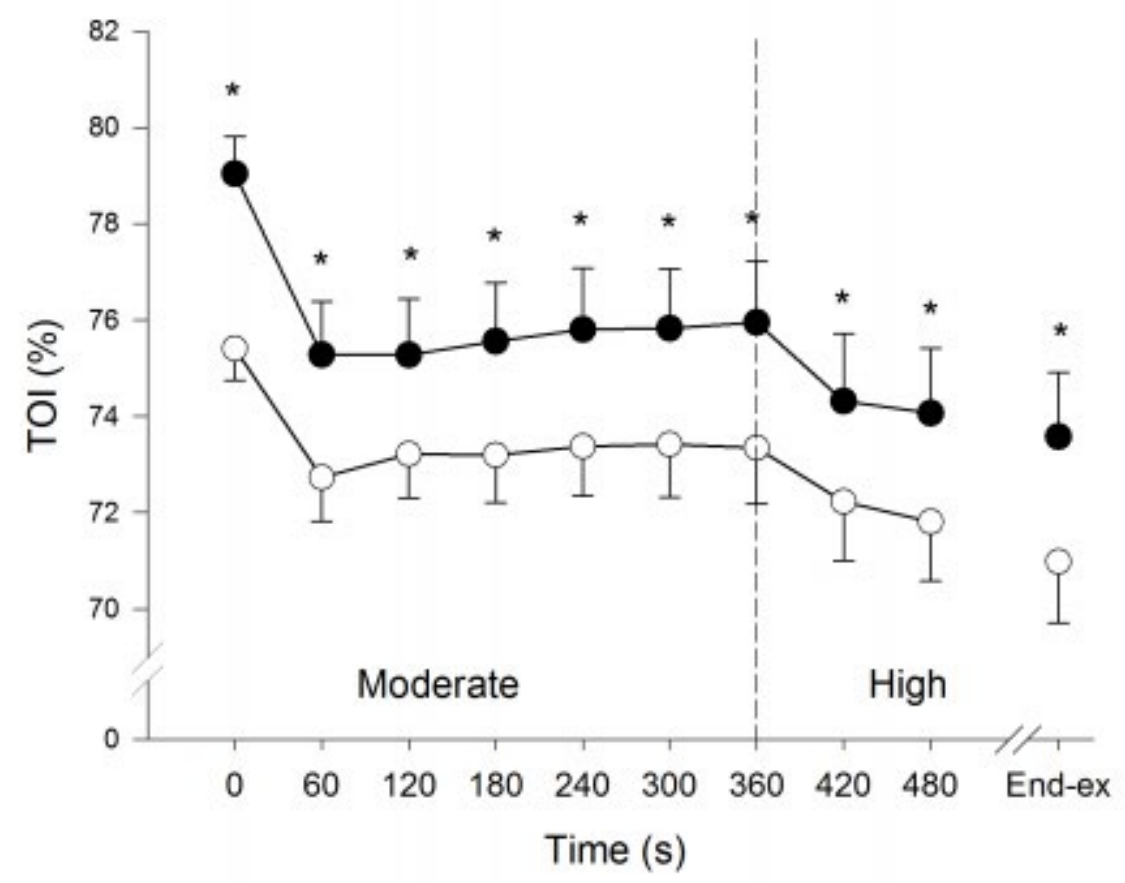


733 Fig 3. Mean \pm SD total oxygenation index (TOI) at moderate and high-intensity exercise during the work-to-work

734 transitions without priming exercise (open circles) and with priming exercise (solid circles) in T2D (A) and

735 healthy controls (B). $* P<0.05$ vs. unprimed within same diabetes status group (i.e. within controls or within 736 Type 2 diabetes).

737 
Figure 4
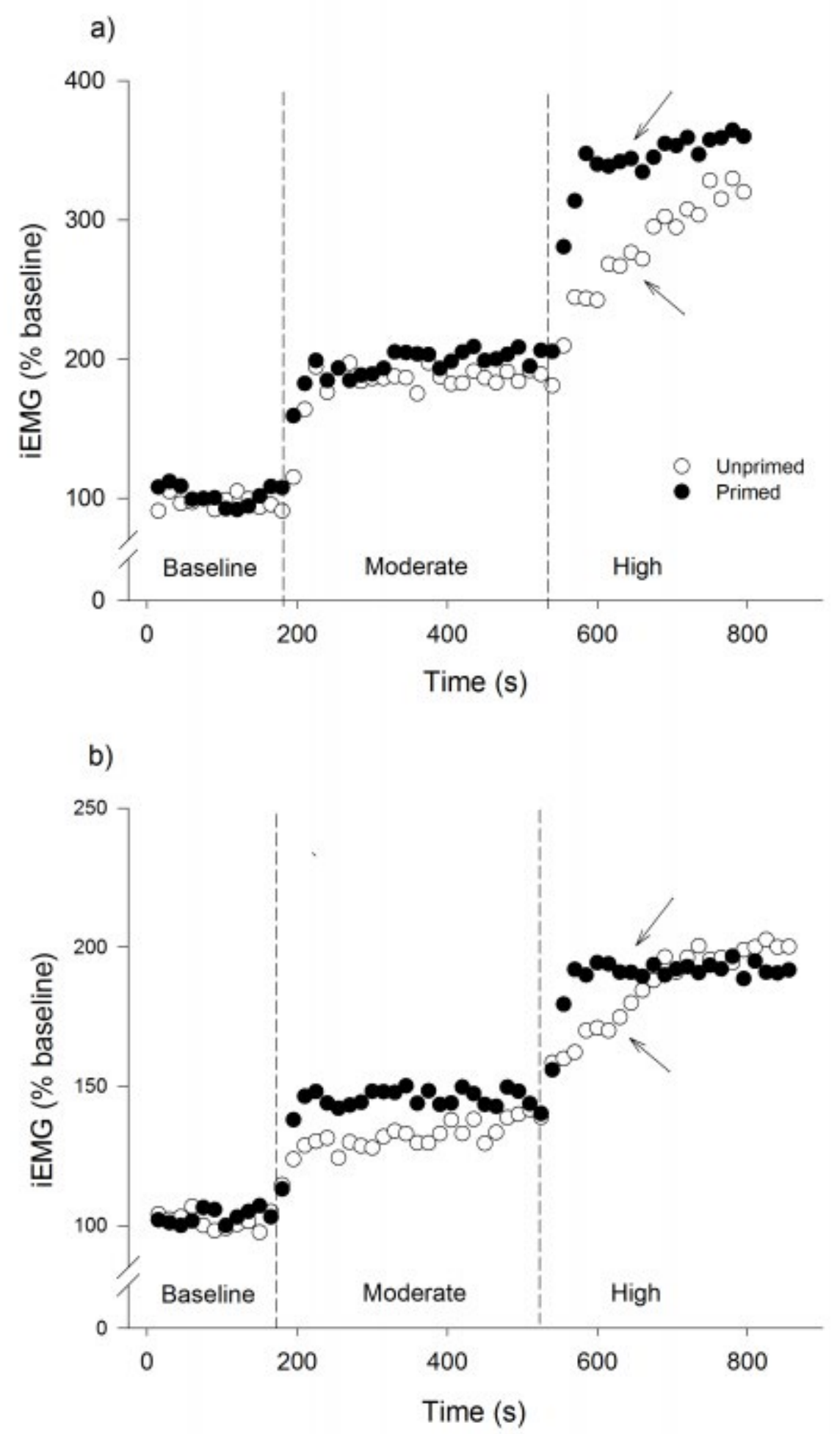

739 Fig 4: Integrated surface electromyographic (iEMG) responses for a representative individual with type 2 diabetes

740 (A) and a healthy control (B) during moderate and high-intensity work-to-work cycling transitions without 
741 priming exercise (open circles) and with priming exercise (solid circles). The arrows indicate the time point 742 equivalent to the onset of the $\dot{\mathrm{V}}_{2}$ slow component.

Figure 5

a)

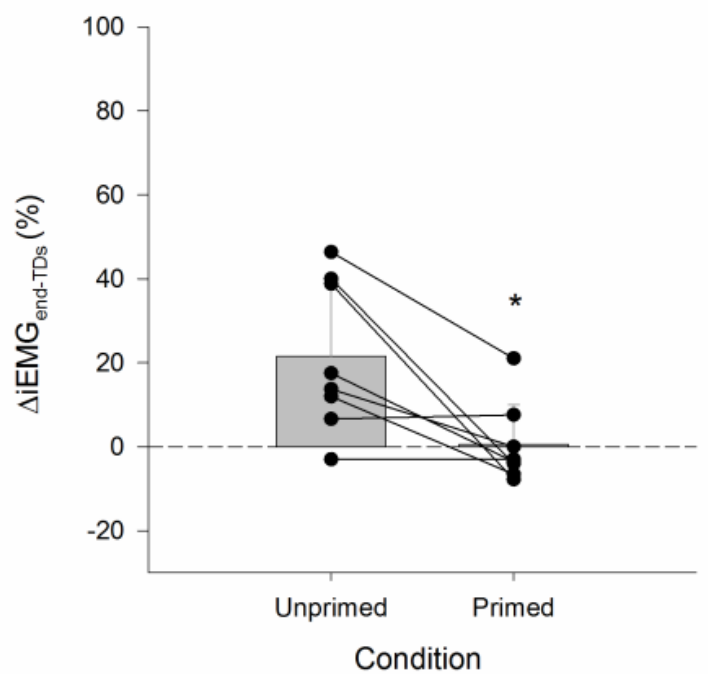

b)

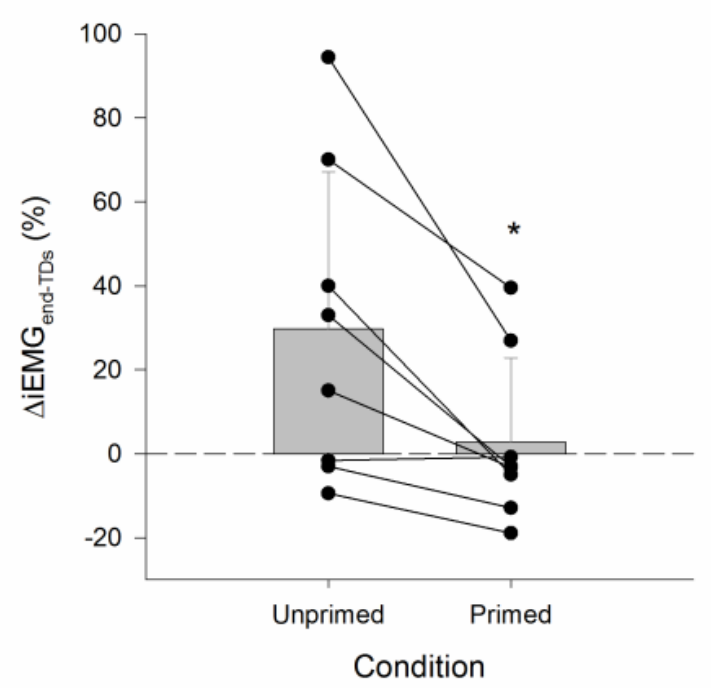

745

746 Fig 5: Individual and mean \pm SD (bar graph) changes in integrated surface electromyographic (iEMG) responses between end-exercise and the time point equivalent to the oxygen uptake slow component $\left(\mathrm{V}_{2} \mathrm{TD}_{\mathrm{s}}\right)\left(\Delta \mathrm{iEMG} \mathrm{G}_{\text {end- }}\right.$ TDs) during high-intensity work-to-work transitions without priming exercise (unprimed) and with priming exercise (primed) in T2D (A) and healthy controls (B). * $P<0.05$ vs. unprimed within same diabetes status group (i.e. within controls or within Type 2 diabetes).

Table 1. Physical characteristics and activity levels.

\begin{tabular}{|l|l|l|l|}
\hline & Controls & T2D & $P$ Value \\
\hline$n$ & 9 & 9 & \\
\hline Physical characteristics & & & \\
\hline Sex (male, female), $n$ & 5,4 & 5,4 & \\
\hline Age, yr & $45 \pm 12$ & $48 \pm 9$ & 0.48 \\
\hline
\end{tabular}




\begin{tabular}{|l|l|l|l|}
\hline Stature, $\mathrm{m}$ & $1.67 \pm 0.07$ & $1.70 \pm 0.08$ & 0.46 \\
\hline BMI, $\mathrm{kg} / \mathrm{m}^{2}$ & $30(4)$ & $28(8)$ & 0.72 \\
\hline Body Mass, $\mathrm{kg}$ & $82.0(8.5)$ & $79.0(32.8)$ & 0.57 \\
\hline Fat layer VL, mm & $12.7(10.2)$ & $6.5(2.8)$ & 0.23 \\
\hline HbAlc, \% & $5.1(0.2)^{*}$ & $6.9(1.4)$ & 0.02 \\
\hline FPG, mmol/L & $4.4 \pm 0.8^{*}$ & $7.2 \pm 1.3$ & 0.01 \\
\hline Time since diagnosis, yr & & $7.3 \pm 4.0$ & 0.59 \\
\hline Total cholesterol, mmol/L & $3.85 \pm 0.88$ & $4.50 \pm 0.77$ & 0.65 \\
\hline LDL-C, mmol/L & $2.14 \pm 0.86$ & $2.43 \pm 0.76$ & 0.10 \\
\hline HDL-C, mmol/L & $1.20 \pm 0.17$ & $1.00 \pm 0.17$ & 0.35 \\
\hline Triglycerides, mmol/L & $1.12 \pm 0.48$ & $2.33 \pm 1.29$ & 0.07 \\
\hline Habitual physical activity & & 0.13 \\
\hline Inactive, $\mathrm{h} /$ day & $19.2 \pm 1.7$ & $18.3 \pm 1.4$ & \\
\hline Light, h/day & $3.8 \pm 1.1$ & $5.1 \pm 1.3$ & $0.48 \pm 0.28$ \\
\hline Moderate, h/day & $0.73 \pm 0.50$ & $0.20(0.25)$ & \\
\hline Vigorous, h/day & & & $0.33)$ \\
\hline
\end{tabular}

Values are means \pm SD for variables that were normally distributed and median with interquartile range in parentheses for variables which showed significant skewness and were not normally distributed in one or both groups. $n$, no. of participants. Some variables have missing values, and the sample sizes are as follows: fat layer vastus lateralis (VL), $n=7$ [nondiabetic control (ND)] and 8 [type 2 diabetes (T2D)]; 
Table 2. Dynamic response characteristics of oxygen uptake $\left(\dot{\mathrm{V}}_{2}\right)$ during moderate-intensity and high-intensity

760 cycling exercise of the work-to-work transitions

761

\begin{tabular}{|c|c|c|c|c|}
\hline & \multicolumn{2}{|c|}{ Unprimed } & \multicolumn{2}{|c|}{ Primed } \\
\hline & Controls & Type 2 diabetes & Controls & Type 2 diabetes \\
\hline$N$ & 9 & 9 & 9 & 9 \\
\hline Moderate-intensity & & & & \\
\hline Baseline $\dot{\mathrm{V}} \mathrm{O}_{2}, \mathrm{~L} / \mathrm{min}$ & $0.77 \pm 0.13$ & $0.89 \pm 0.27$ & $0.82 \pm .11$ & $0.90 \pm 0.23$ \\
\hline$\dot{\mathrm{V}} \mathrm{O}_{2} \mathrm{~A}_{\mathrm{p}}, \mathrm{L} / \mathrm{min}$ & $0.82 \pm 0.44$ & $0.50 \pm 0.21$ & $0.85 \pm 0.51$ & $0.51 \pm 0.19$ \\
\hline$\dot{\mathrm{V}} \mathrm{O}_{2} \tau_{\mathrm{p}}, \mathrm{s}$ & $34.6 \pm 7.3 \dagger$ & $43.8 \pm 11.2$ & $25.6 \pm 7.7 \dagger^{*}$ & $33.2 \pm 11.5^{*}$ \\
\hline $\mathrm{Cl}_{95} \dot{\mathrm{V}}_{2} \tau_{\mathrm{p}}, \mathrm{s}$ & $4.4 \pm 2.1$ & $5.1 \pm 1.9$ & $4.0 \pm 1.2$ & $4.7 \pm 0.8$ \\
\hline$\dot{\mathrm{V}} \mathrm{O}_{2}$ end $\mathrm{A}, \mathrm{L} / \mathrm{min}$ & $1.64 \pm 0.54$ & $1.44 \pm 0.39$ & $1.73 \pm 0.65$ & $1.43 \pm 0.33$ \\
\hline$\dot{\mathrm{V}} \mathrm{O}_{2} \mathrm{G}_{\mathrm{p}} \mathrm{mL} \cdot \mathrm{min}^{-1} \cdot \mathrm{W}^{-1}$ & $9.6 \pm 1.7$ & $9.4 \pm 2.5$ & $9.3 \pm 2.3$ & $9.5 \pm 2.3$ \\
\hline High-intensity & $5.1 \pm 1.9$ & $5.1 \pm 1.9$ & $5.1 \pm 1.9$ & $5.1 \pm 1.9$ \\
\hline Baseline $\dot{\mathrm{V}}_{2}, \mathrm{~L} / \mathrm{min}$ & $1.64 \pm 0.54$ & $1.44 \pm 0.39$ & $1.73 \pm 0.65$ & $1.43 \pm 0.33$ \\
\hline$\dot{\mathrm{V}} \mathrm{O}_{2} \mathrm{~A}_{\mathrm{p}}, \mathrm{L} / \mathrm{min}$ & $0.53 \pm 0.15 \dagger$ & $0.33 \pm 0.12$ & $0.55 \pm 0.15 \dagger^{*}$ & $0.40 \pm 0.16^{*}$ \\
\hline$\dot{\mathrm{V}} \mathrm{O}_{2} \tau_{\mathrm{p}}, \mathrm{s}$ & $43.6 \pm 9.8 \dagger$ & $58.6 \pm 16.6$ & $37.7 \pm 6.9$ & $37.2 \pm 19.9^{*}$ \\
\hline $\mathrm{CI}_{95} \dot{\mathrm{VO}}_{2} \tau_{\mathrm{p}}, \mathrm{s}$ & $8.8 \pm 2.4$ & $8.7 \pm 2.9$ & $9.0 \pm 1.9$ & $8.0 \pm 2.8$ \\
\hline$\dot{\mathrm{V}} \mathrm{O}_{2} \mathrm{~A}_{\mathrm{s}}, \mathrm{L} / \mathrm{min}$ & $0.21 \pm 0.13$ & $0.16 \pm 0.09$ & $0.13 \pm 0.09 *$ & $0.11 \pm 0.04 *$ \\
\hline$\dot{\mathrm{V}} \mathrm{O}_{2} \mathrm{~A}_{\mathrm{s}}, \%$ & $27.5 \pm 10.3$ & $32.7 \pm 11.0$ & $18.5 \pm 10.6^{*}$ & $22.5 \pm 7.5^{*}$ \\
\hline$\dot{\mathrm{V}} \mathrm{O}_{2} \mathrm{TD}_{\mathrm{s}}, \mathrm{s}$ & $127 \pm 47$ & $119 \pm 7$ & $129 \pm 50$ & $106 \pm 43$ \\
\hline$\dot{\mathrm{V}} \mathrm{O}_{2}$ end $\mathrm{A}, \mathrm{L} / \mathrm{min}$ & $2.37 \pm 0.61$ & $1.93 \pm 0.50$ & $2.41 \pm 0.66$ & $1.95 \pm 0.50$ \\
\hline$\dot{\mathrm{V}} \mathrm{O}_{2} \mathrm{MRT}, \mathrm{s}$ & $73 \pm 15 \dagger$ & $94 \pm 31$ & $57 \pm 17^{*}$ & $59 \pm 22 *$ \\
\hline $\mathrm{CI}_{95} \dot{\mathrm{VO}}_{2} \mathrm{MRT}, \mathrm{s}$ & $7.4 \pm 2.3$ & $7.9 \pm 1.4$ & $7.1 \pm 2.1$ & $7.1 \pm 2.5$ \\
\hline 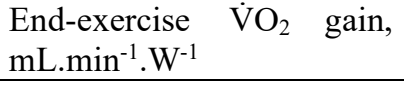 & $11.2 \pm 1.6$ & $10.3 \pm 1.7$ & $11.0 \pm 1.9$ & $10.2 \pm 1.7$ \\
\hline
\end{tabular}

762 Values are means \pm SD; $n=$ no. of participants. A, amplitude; $\tau$, time constant; end A, steady-state oxygen uptake

$763\left(\dot{\mathrm{V}}_{2}\right)$ response; $\mathrm{CI}_{95} 95 \%$ confidence interval; $\mathrm{G}$, oxygen uptake $\left(\dot{\mathrm{V}}_{2}\right)$ gain; $\mathrm{TD}$, time delay; $\mathrm{p}$, primary phase; $\mathrm{s}$

764 slow component phase.

$765 * \mathrm{P}<0.05$ vs. unprimed within same diabetes status group (i.e. within controls or within Type 2 diabetes). $\dagger \mathrm{P}<$ 